\title{
吗啡类生物碱的合成研究进展
}

\author{
李其林 $a, b$ 张洪涁*, \\ ( ${ }^{a}$ 云南省地震局 昆明 650224) \\ ( ${ }^{b}$ 云南大学教育部自然资源药物化学重点实验室 昆明 650091)
}

\begin{abstract}
摘要 吗啡是从鸦片中分离得到的天然产物. 因吗啡及其类似物具有独特的结构和有效的生物活性, 合成化学家对其 合成研究产生了高度的兴趣. 按合成吗啡及其类似物的时间顺序分类, 对吗啡类生物碱的合成研究进展进行了综述.

关键词 吗啡; 吗啡类生物碱; 合成
\end{abstract}

\section{Research Progress on the Synthesis of Morphine Alkaloids}

\author{
Li, Qilin ${ }^{a, b} \quad$ Zhang, Hongbin ${ }^{*, b}$ \\ ( ${ }^{a}$ Earthquake Administration of Yunnan Province, Kunming 650224)
}

( ${ }^{b}$ Key Laboratory of Medicinal Chemistry for Natural Resource Ministry of Education, Yunnan University, Kunming 650091)

\begin{abstract}
The morphine alkaloids constitute a class of structurally related natural products isolated from opium poppy, $P a-$ paver somniferum. The synthesis of morphine and its derivatives has attracted the attention of many generations of synthetic chemists due to their highly challenging molecular architecture and biological activities. Progresses toward the synthesis of the morphine alkaloids are reviewed in terms of chronological order.

Keywords morphine; morphine alkaloids; synthesis
\end{abstract}

吗啡 1 (Morphine)是从鸦片中分离得到的生物碱, 其重量约占鸦片重量的 $14 \% \sim 17 \% \%^{[1]}$, 是人们熟知的一 种麻醉剂及镇痛药物, 但具有成瘾性. 其他天然的吗啡 类生物碱还包括可待因 2 (Codeine)、蒂巴因 3 (Thebaine) 和可待因酮 4 (Codeinone)等(图 1). 吗啡及其类似物独 特的结构和生物活性引起了合成化学家高度的兴趣. 天 然的(一)-morphine 是具有 $\mathrm{ABCDE}$ 五个环稠合而成的复 杂立体结构分子, 其含有一个五元二氢呋喃环、一个含 氮的桥环、五个连续的手性中心, 其中一个是苄位的季 碳中心. 吗啡被认为是合成化学家们心目中极具重要意 义的合成目标. 距盖茨第一次合成吗啡到今天的 60 多 年里, 至少有 30 个研究组致力于吗啡及其类似物的全 合成研究工作，吗啡全合成的相关报道己有近 50 余篇, 关于吗啡合成的综述也有近 8 篇 ${ }^{[2 \sim 9]}$. 本文按合成的时 间顺序分类综述了吗啡类生物碱的全合成研究进展.

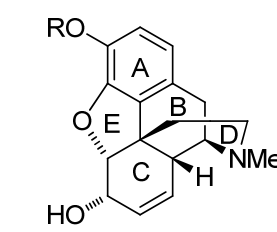

1: $\mathrm{R}=\mathrm{H},(-)$-morphine 2: $R=$ Me, (-)-codeine

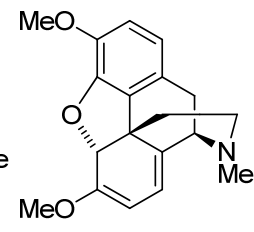

3: (-)-Thebaine

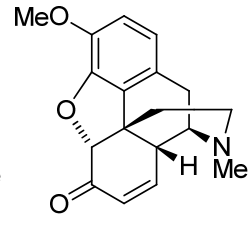

4: (-)-codeinone
图 1 天然的吗啡类生物碱

Figure 1 Natural opium alkaloids

\section{1 吗啡类生物碱的合成}

距离 1806 年吗啡首次从罂粟中成功分离出来到今 天，已经过去了两百多个年头. 吗啡的首次全合成于 1952 年由 Gates 课题组完成, 在此之后, 每一个十年中 均有关于吗啡的全合成文章发表. 在众多吗啡的合成研 究中, 涌现了相当大批的新的有效合成方法和新颖的合 成策略.

\footnotetext{
* Corresponding author. E-mail: zhanghb@ynu.edu.cn Received January 28, 2017; revised March 22, 2017; published online April 13, 2017. Foundation of China (Nos. 20925205, 21332007).

长江学者和创新团队发展计划(No. IRT13095)、国家自然科学基金(Nos. 20925205, 21332007)资助项目.
}

Project supported by the Program for Changjiang Scholars and Innovative Research Team in University (No. IRT13095), and the National Natural Science 


\subsection{Gates 研究组的合成方法}

1952 年, 盖茨 (Gates) 对吗啡的 ${ }^{[10,11]}$ 首次合成 (Scheme 1) 被视为全合成领域中的经典之作. 盖茨以化 合物 5 作为起始原料经 9 步反应合成 Diels-Alder 反应的 前体 6 , 化合物 6 与丁二烯在加热条件下发生分子间的 Diels-Alder 反应形成化合物 7. 再经铜一铬催化加氢反应 获得关键中间体 8 , 但很遗憾 C(14)位上氢的相对立体 构型与天然产物相反. 关键中间体 8 经 Wolf-Kishner-黄 鸣龙还原, $\mathrm{N}$ 上甲基化和 $\mathrm{LiAlH}_{4}$ 还原酰胺得到化合物 9. 消旋的化合物 9 经酒石酸拆分得 $C(9)$ 和 $C(13)$ 立体构型 与天然产物一致但 $\mathrm{C}(14)$ 与天然产物相反的中间体. 该 中间体构型经天然 Codeine 的降解物得以证实, 这也进 一步证实了 Robinson 对吗啡结构的推测 ${ }^{[12]}$. 而后的合 成步骤以天然 Codeine 的降解物为原料出发经区域选择 性水合反应，脱甲基反应和 Oppennauer 氧化反应得化 合物 10. 之后经羰基 $\alpha$ 位溴代和苯环溴代, 再与 2,4-二 硝基苯肼反应成腙后水解得到化合物 11, 此时 C(14)的 立体构型翻转为热力学稳定的正确天然产物构型. 化合 物 11 经双键氢化、溴代，再与 2,4-二硝基苯肼反应构筑 了二氢呋喃环, 水解腙得到 $\alpha, \beta$-不饱和酮化合物, $\mathrm{LiAlH}_{4}$ 还原羰基及苯基溴, 最终以 31 步 $0.06 \%$ 的总
收率第一次合成天然产物吗啡, 用全合成的方式证明了 吗啡的结构.

\subsection{Ginsburg 研究组的合成方法}

继 Gates 之后, 1954 年 Ginsburg 研究组 ${ }^{[13]}$ 报道了合 成吗啡的另一路线 (Scheme 2), 尽管只完成了吗啡的 形式合成，但为合成吗啡及其类似物提供了新的策略. 该路线在化合物 16 的基础上利用迈克尔加成反应及分 子内的傅克酰基化反应为关键步骤合成化合物 19. 出 其不意的是在将酮崖基选择性保护为缩酮后，苯环上的 甲氧基被切断, 直链上的乙酰基失去发生了亲核取代反 应，从而构建了含芳环季碳中心，同时建立了吗啡的四 环骨架结构得到化合物 20. 之后经保护、去保护和还原 作用合成盖茨的中间体 $\mathbf{1 0}$ (dihydrothebainone).

\subsection{Barton、Szantay 和 White 研究组的合成方法}

1964 年, Barton 课题小组 ${ }^{[14]}$ (Scheme 3)从吗啡可能 的生源途径 ${ }^{[15]}$ (图 2)中 $(R)$-网脉碱 $\mathbf{2 5}$ 经邻对位苯酚的氧 化自由基偶联反应生成沙罗泰里啶 $\mathbf{2 6}$ 的过程得到启发, 第一次利用化学方法模拟了这一生源合成途径, 尽管这 个反应只有 $0.02 \%$ 的收率. 之后 Szantay 和 White 等 ${ }^{[16 ~ 18]}$ (Scheme 3)纷纷采用苯酚的氧化自由基偶联的 策略对吗啡进行了合成.<smiles>Oc1ccc2cc(O)ccc2c1</smiles>

5

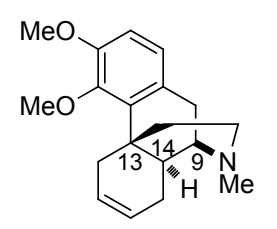

9<smiles>COc1cc(Br)c2c3c1O[C@H]1C(=N)C=C[C@H](C2)[C@]31CCN</smiles>

13<smiles>COc1ccc2c(c1OC)C(CC#N)=CC(=O)C2=O</smiles>

6

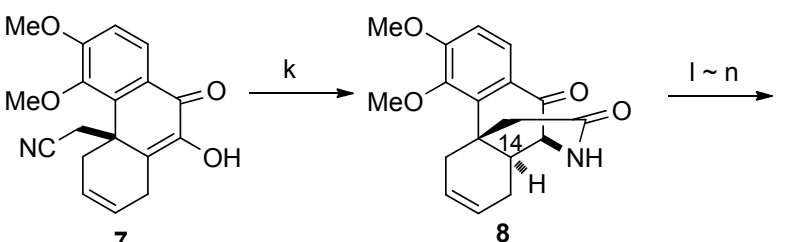
7

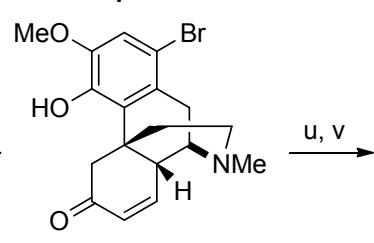

11

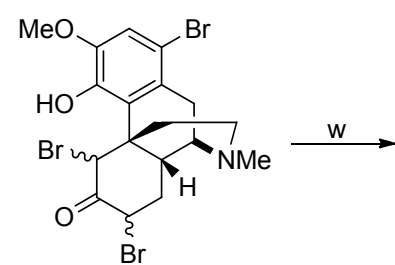

12

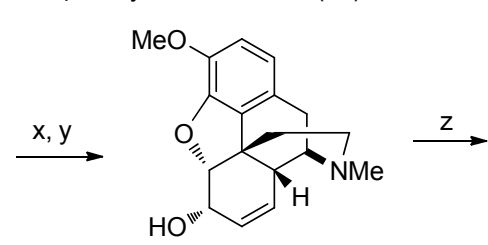

Codeine (2)

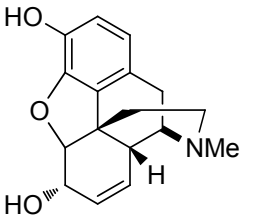

morphine (1)

Reagents and conditions: (a) $\mathrm{BzCl}, \mathrm{Py}$; $\mathrm{NaNO}_{2}, \mathrm{HOAc}$; (b) $\mathrm{H}_{2}, \mathrm{Pd} / \mathrm{C}$; (c) $\mathrm{FeCl}_{3}$; (d) $\mathrm{SO}_{2} ; \mathrm{Me}_{2} \mathrm{SO}_{4}, \mathrm{~K}_{2} \mathrm{CO}_{3}$; (e) $\mathrm{KOH}$; $\mathrm{NaNO}_{2}, \mathrm{HOAc}_{2} \mathrm{H}_{2}$ $\mathrm{Pd} / \mathrm{C}$; (f) $\mathrm{FeCl}_{3}$; (g) $\mathrm{EtOOCCH}_{2} \mathrm{CN}, \mathrm{Et}_{3} \mathrm{~N}$; (h) $\mathrm{K}_{3} \mathrm{Fe}(\mathrm{CN})_{6}$; (i) $\mathrm{KOH}, 20 \%$ nine steps; (j) butadiene, $\Delta$; (k) $\mathrm{H}_{2}$, Cu chromite; (l) $\mathrm{N}_{2} \mathrm{H}_{4}, \mathrm{KOH}$, DEG,155 ${ }^{\circ} \mathrm{C}$, 92\%; (m) NaH, Mel; (n) $\mathrm{LiAlH}_{4}, 87.5 \%$ two steps; (o) (+)-dibenzoyltartaric acid; $\mathrm{H}_{2} \mathrm{SO}_{4}, \mathrm{H}_{2} \mathrm{O}, 28 \%$; (p) $\mathrm{KOH}, \mathrm{N}_{2} \mathrm{H}_{4}$, $\left(\mathrm{CH}_{2} \mathrm{OH}\right)_{2}, \Delta, 54 \%$; (q) $t$-BuOK, $\mathrm{Ph}_{2} \mathrm{CO}, 89.6 \%$; (r) $\mathrm{Br}_{2}$; (s) 2,4-DNPH; (t) $\mathrm{HCl}, \mathrm{H}_{2} \mathrm{O}, \mathrm{Me}_{2} \mathrm{CO}$; (u) $\mathrm{H}_{2}, \mathrm{PtO}_{2}$; (v) $\mathrm{Br}_{2}$; (w) 2,4-DNPH; Py, $\Delta$; (x) $\mathrm{HCl}, \mathrm{H}_{2} \mathrm{O}, \mathrm{Me}_{2} \mathrm{CO}$; (y) $\mathrm{LiAlH}_{4}$; (z) $\mathrm{Py} \cdot \mathrm{HCl}, 220^{\circ} \mathrm{C}$.

图式 1 Gates 研究组的合成方法

Scheme 1 Synthesis by Gates's group 
<smiles>COc1cccc(C2=CCCCC2)c1OC</smiles>

14<smiles>C=C1CC2CCCC3(OCCO3)C2c2c1ccc(OC)c2OC</smiles>

18<smiles>COc1cccc(C2(Cl)CCCCC2=O)c1OC</smiles>

15<smiles>COc1ccc2c(c1OC)[C@]1(CCCC(=O)C1)[C@@H](NC(=O)COC(C)=O)C2=O</smiles>

19<smiles>COc1cccc(C2=CCCCC2=O)c1OC</smiles>

16 $\mathrm{MeO}$

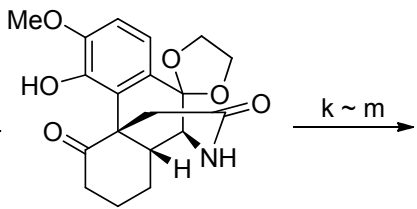

20<smiles>COc1cccc(C2C(=O)CCCC2CC(=O)O)c1OC</smiles>

17<smiles>COc1ccc2c(c1O)[C@@]1(CC2)CC(=O)CC[C@H]1NC(=O)O</smiles>

21

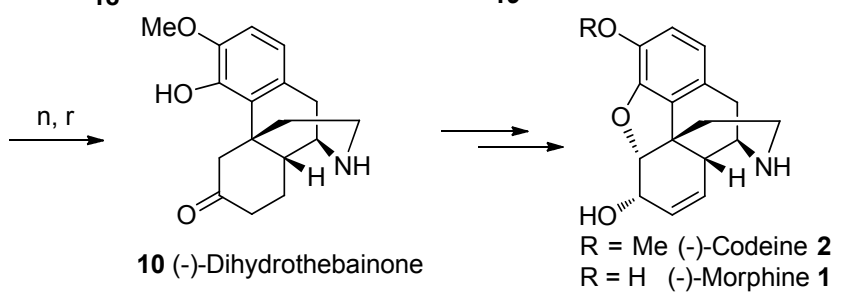

Reagents and conditions: (a) NOCl; (b) Py, D; $\mathrm{H}_{2} \mathrm{SO}_{4}, \mathrm{H}_{2} \mathrm{O}$; (c) $t$-BuOK, $\mathrm{CH}_{2}(\mathrm{COOBn})_{2}$; (d) $\mathrm{H}_{2}$, Pd/C; D; (e) HF; (f) TsOH, $\left(\mathrm{CH}_{2} \mathrm{OH}\right)_{2}$; (g) $\mathrm{NaOEt}, n$ AmONO; (h) $\mathrm{H}_{2}, \mathrm{Pd} / \mathrm{C}, \mathrm{HCl}$, EtOH; (i) $\mathrm{AcOCH}_{2} \mathrm{COCl}, \mathrm{Py}, \mathrm{CHCl}_{3}$; (j) TsOH, $\left(\mathrm{CH}_{2} \mathrm{OH}\right)_{2}, \mathrm{PhMe}, \mathrm{PhH}, \Delta$; (k) NaOEt, $n$-AmONO; (l) HCl, $\mathrm{H}_{2} \mathrm{O}, \mathrm{EtOH}, \Delta$; (m) $\mathrm{N}_{2} \mathrm{H}_{4}$, DEG; $165^{\circ} \mathrm{C}$; (n) HCl, $\mathrm{H}_{2} \mathrm{O}$, EtOH, $\Delta$; (o) $\mathrm{LiAlH}_{4}$, THF; (p) HCHO, HCOOH; (q) $t$-BuOK, PhCO, PhH; (r) (+)-tartaric acid; $\mathrm{NH}_{4} \mathrm{OH}$.

图式 2 Ginsburg 研究组的合成方法

Scheme 2 Synthesis by Ginsburg's group<smiles>CC#CCOc1cc2c(cc1O)CCNC2Cc1ccc(O)cc1</smiles>

22 L-Tyrosine<smiles>COC1=CC2(CC(C)c3ccc(OC)c(O)c32)C(C(C)(C)C)=CC1=O</smiles>

23 (S)-Norcoclauline

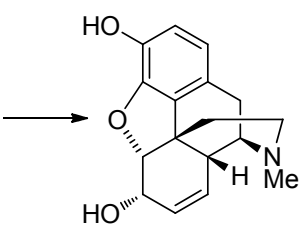

1 Morphine<smiles>COc1ccc(C[C@H]2c3cc(O)c(O)cc3CCN2C)cc1O</smiles>

24 (S)-Reticuline

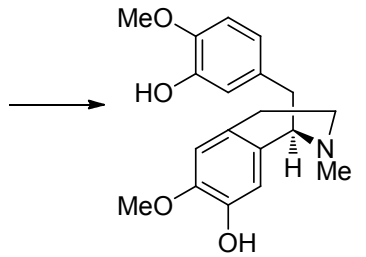

25 (R)-Reticuline

图 2 吗啡可能的生源途径

Figure 2 Biosynthesis of morphine alkaloids

\subsection{Rice 研究组的合成方法}

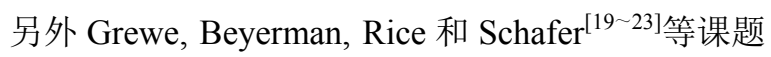
小组也对吗啡的仿生合成产生了浓厚的兴趣, 以 Grewe 环化为关键步骤来合成吗啡类生物碱(Scheme 3). 其中, Rice 课题小组在 1980 年完成的合成路线最具代表性. 从原料酸化合物 34 和胺化合物 35 出发经过一步缩合成 酰胺, 之后发生一步 Bischler-Napieralski 反应和氰基硼 氢化钠还原得到化合物 36. 伯奇 Birch 还原和 $\mathrm{N}$ 上甲酰 化得到化合物 37, 缩酮保护和芳香环溴代以占位的方
式保护芳环对位不会受接下来的反应影响, 两步反应得 到 Grewe 环化的前体 38, 在甲酸的作用下形成 $\beta, \gamma$-不饱 和酮之后在氢氟酸/氟化铵的条件下得到正离子促进的 关环产物，后经去甲酰化和还原胺化得到化合物 39, 随 后经过一步羰基 $\alpha$ 位溴代和苯酚去质子化作用关环构筑 二氢呋喃环, 芳环上的溴原子在甲醛存在下加氢移除后 得到二氢可待因酮 40 (dihydrocodeinone). Rice 小组以 $29.7 \%$ 的总收率共用 14 步最终完成了吗啡的形式全合 成(Scheme 4). 
Barton Group<smiles>COc1ccc(CC2(C)CCC2(C)N(C)C)cc1O</smiles>

27

$\mathrm{MnO}_{2}$ or $\mathrm{K}_{3} \mathrm{Fe}(\mathrm{CN})_{6}$

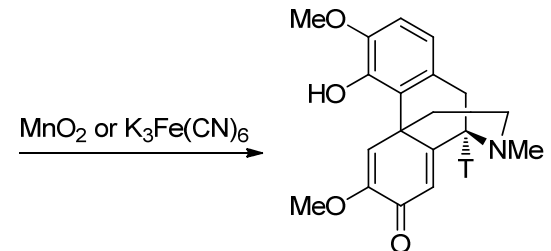

26 Salutaridine

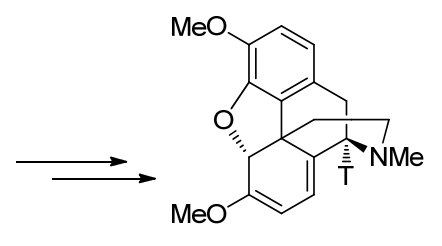

3 Thebaine

Szantay Group<smiles>COc1ccc(CC2c3cc(O)c(OC)cc3CCN2C)cc1O</smiles>

28

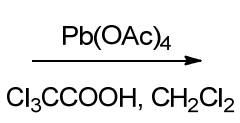

$\mathrm{Cl}_{3} \mathrm{CCOOH}, \mathrm{CH}_{2} \mathrm{Cl}_{2}$

29 14\%<smiles>COC1=CC2(CCC(C)C2)c2c(ccc(OC)c2O)CC1=O</smiles>

$302.7 \%$

White Group<smiles>COc1cc(CC2CN(Cc3cc(O)c(O)cc3Br)CC2C(F)(F)F)cc(O)c1O</smiles>

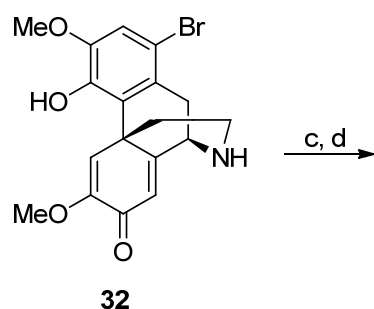<smiles>COC1=CC=C2C(OC)[C@H]3Oc4c(OC)cc(Br)c5c4[C@@]23CC1CN5C</smiles>

33<smiles>CNC1CC2CC3C=CC(O)[C@@H]4Oc5c(OC)ccc(c54)C32C1</smiles>

2 Codeine

Reagents and conditions: (a) $\mathrm{Phl}\left(\mathrm{OCOCF}_{3}\right)_{2}, \mathrm{CH}_{2} \mathrm{Cl}_{2},-40{ }^{\circ} \mathrm{C}, 21 \%$; (b) $\mathrm{K}_{2} \mathrm{CO}_{3}, \mathrm{H}_{2} \mathrm{O}, \mathrm{MeOH}$; (c) $\mathrm{HCHO}, \mathrm{H}_{2} \mathrm{O}, \mathrm{NaBH}_{4}, 37 \%$ two steps; (d) $\mathrm{HC}(\mathrm{OR})_{2} \mathrm{NMe}_{2}, \mathrm{CH}_{2} \mathrm{Cl}_{2}, 80 \%$; (e) $\mathrm{Hg}(\mathrm{OAc})_{2}, \mathrm{HCOOH}, \mathrm{H}_{2} \mathrm{O} ; \mathrm{HCl} ; \mathrm{NaOH}$; (f) $\mathrm{LiAlH}_{4}, 25 \%$ two steps.

图式 3 Barton、Szantay 和 White 研究组的合成方法

Scheme 3 Synthesis by Barton, Szantay and White's group<smiles>COc1cccc(CCN)c1</smiles>

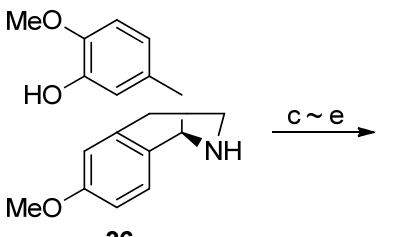<smiles>COc1ccc(C)cc1O</smiles><smiles>COc1cc(Br)c(C)cc1O</smiles>

38<smiles></smiles>

39

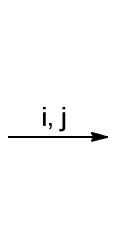

(n)

40 dihydrocodeinone

Reagents and conditions: (a) $200{ }^{\circ} \mathrm{C}, 95 \%$; (b) $\mathrm{POCl}_{3}, \mathrm{MeCN}, \Delta$; $\mathrm{NaBH}_{3} \mathrm{CN}, \mathrm{MeOH}, \mathrm{pH} 4 \sim 5,86 \%$; (c) $\mathrm{Li}, \mathrm{NH}_{3}, t-\mathrm{BuOH}, 90 \%$; (d) $\mathrm{HCOOPh}$ $\Delta$, 94\%; (e) MsOH, $\left(\mathrm{CH}_{2} \mathrm{OH}\right)_{2}$, THF, $100 \%$; (f) $\mathrm{N}$-bromoacetamide; (g) $\mathrm{HCOOH}, \mathrm{H}_{2} \mathrm{O}, 88 \%$; (h) $\mathrm{NH}_{4} \mathrm{NF} \bullet \mathrm{HF}$; TfOH, $60 \%$; (i) $\mathrm{HCl}, \mathrm{H}_{2} \mathrm{O}, \mathrm{MeOH}$; (j) $\mathrm{H}_{2}, \mathrm{Pd} / \mathrm{C}, \mathrm{HOAc} ; \mathrm{HCHO}, \mathrm{NaOAc}, 92 \%$.

图式 4 Rice 研究组的合成方法

Scheme 4 Synthesis by Rice's group

\subsection{Evans 研究组的合成方法}

1982 年, Evans 小组 ${ }^{[24]}$ 合成吗啡类生物碱的路线是 先利用芳基锂试剂与羰基反应合成化合物 43 , 继而烯 丙位上的氢去质子化后双键迁移与二溴代物发生亲核 取代、烯胺烷基化得化合物 45. 烯胺质子化的亚胺在环
丙烷重氮甲烷的作用下发生环丙烷化后经二甲亚砜氧 化开环得关键中间体化合物 48. 在路易斯酸催化下分 子内傅克反应构筑了吗啡骨架的 $\mathrm{B}$ 环, 羟基磺酰化被还 原脱除, 端烯被氧化切断得到 $\mathrm{H}$ 构型与 Gates 的中间体 相反的化合物 50, 完成了吗啡的形式全合成(Scheme 5). 


\subsection{Rapport 研究组的合成方法}

Rapport 研究组 ${ }^{[25]}$ 于 1983 年试图合成吗啡, 但在合 成过程中遇到了许多立体化学的问题, 导致最终合成只 能止步于 Evans 的合成中间体. 首先不饱和化合物 51 发生 Michael 加成反应和还原氧基酰胺化得到化合物 52, 随后甲基化、选择性还原酰胺得到六氢吡啶-3-羧酸 酯化合物 53. 六氢吡啶-3-羒酸酯发生 Methylene-lactam 重排、烯丙位氧化和酯交换后得 Claisen 重排前体 55, 化 合物 55 继而 Claisen 重排、酯同系化、Michael 加成和 脱羧后合成化合物 57. 之后 Rapport 曾尝试利用亲核反
应关吗啡骨架 B 环, 但因立体化学始终不对的问题，只 能合成得到 Evans 的合成中间体(Scheme 6).

\subsection{Schultz 研究组的合成方法}

1985 年, Schultz 等 ${ }^{[26]}$ 合成吗啡的亮点在于利用光 反应合成吗啡骨架二氢呋喃 $\mathrm{E}$ 环的同时建立了正确立 体构型的含芳环季碳中心. 该路线首先合成得到环氧化 合物 59, 在碱性条件下苯酚对环氧开环并脱除成双键 得到醚类化合物 $\mathbf{6 0}$. 之后在光反应条件下成功构筑了 苯并呋喃环，后将羰基保护、还原酰胺脱除成双键，随 后氧基被甲基锂亲核加成成甲基酮化合物 65. 化合物<smiles>CCNCC=Cc1cccc(OC)c1OC</smiles>

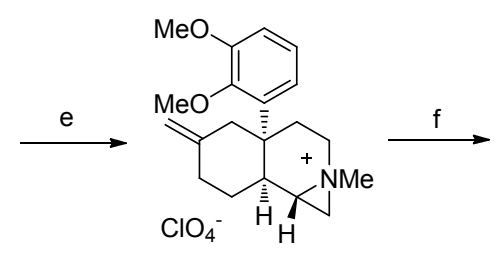

47

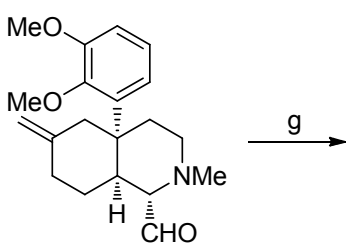

48

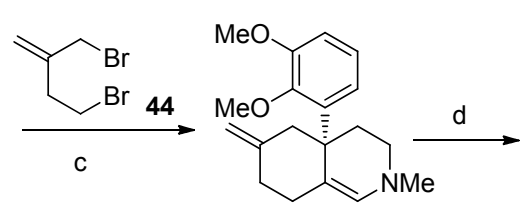

45

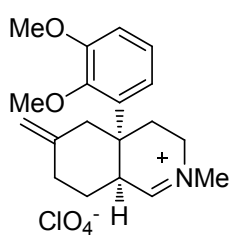

46

cis $:$ trans $=95: 5$

Reagents and conditions: (a) $\mathrm{Et}_{2} \mathrm{O}, 0{ }^{\circ} \mathrm{C}, 45 \% \sim 50 \%$; (b) TsOH, PhMe, $\Delta, 95 \%$; (c) 44, BuLi; $\mathrm{Nal}, \mathrm{K}_{2} \mathrm{CO}_{3}, \mathrm{MeCN}$; (d) $\mathrm{HCl} 60 \%$, two steps; (e) $\mathrm{CH}_{2} \mathrm{~N}_{2}, \mathrm{Et}_{2} \mathrm{O}-\mathrm{CH}_{2} \mathrm{Cl}_{2}, 95 \%$; (f) $\mathrm{Me}_{2} \mathrm{SO}, 23{ }^{\circ} \mathrm{C}, 100 \%$; (g) $\mathrm{BF}_{3} \cdot \mathrm{Et}_{2} \mathrm{O}, \mathrm{PhMe},-10{ }^{\circ} \mathrm{C}, 80 \%$; (h) MsCl, $\mathrm{Et}_{3} \mathrm{~N}$; LiBEt $3 \mathrm{H}, 90 \%$; (i) $\mathrm{OsO}_{4}, \mathrm{NalO}_{4}, \mathrm{H}_{2} \mathrm{O}$, HOAc, THF, $90 \%$.

图式 5 Evans 研究组的合成方法

Scheme 5 Synthesis by Evans' group

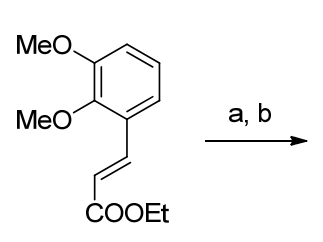

51

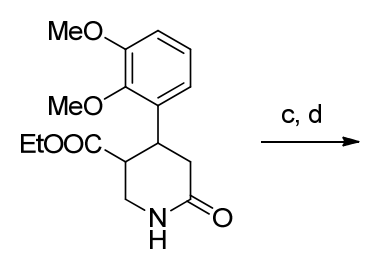

52

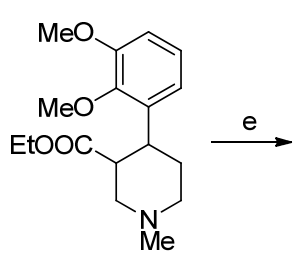

53

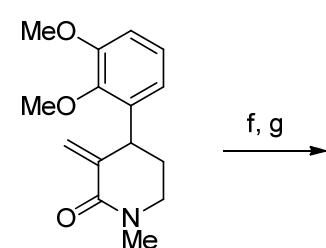

54<smiles>COCC1=C(c2cccc(OC)c2OC)CCN(C)C1=O</smiles>

55

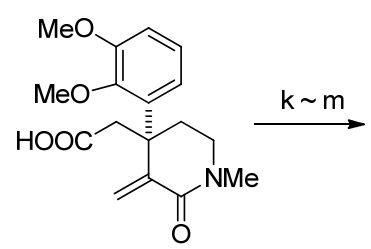

56

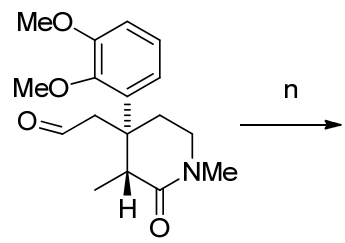

57

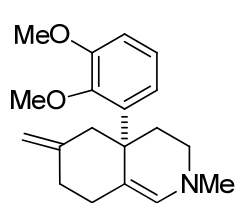

Evans' intermediate

Reagents and conditions: (a) EtOOCCH${ }_{2} \mathrm{CN}, \mathrm{NaOEt}, 93 \%$; (b) $\mathrm{H}_{2}, \mathrm{PtO}_{2}, \mathrm{HCl}, \mathrm{EtOH} ; \mathrm{PhMe}, \Delta, 85 \% ;(\mathrm{c}) \mathrm{Me}_{3} \mathrm{OBF} 4, \mathrm{CH}_{2} \mathrm{Cl}_{2} ; \mathrm{NaBH}_{4}, \mathrm{EtOH}$ $82 \%$; (d) $\mathrm{HCHO}, \mathrm{H}_{2}, \mathrm{Pd} / \mathrm{C}$, EtOH, 94\%; (e) NaOH; $\mathrm{HOAc}$; $\mathrm{Ac}_{2} \mathrm{O}, \Delta, 99 \%$; (f) $\mathrm{SeO}_{2}, \mathrm{PhCl}_{1} 100{ }^{\circ} \mathrm{C}, 55 \%$; (g) $\mathrm{HCOOH}, 50 \% \sim 85 \%$; (h) $\mathrm{K}_{2} \mathrm{CO}$, $\mathrm{MeOH}, 90 \%$; (i) $\mathrm{MeC}(\mathrm{OMe})_{3}$, pivalic acid, $\Delta, 70 \%$; (j) $\mathrm{NaOH}$; (k) $\mathrm{Im}_{2} \mathrm{CO}, \mathrm{CH}_{2} \mathrm{Cl}_{2} ; \mathrm{CH}_{2}\left(\mathrm{COOBu}_{2}\right)_{2} ;(\mathrm{I}) \mathrm{NaOMe}, \mathrm{MeOH}, 98 \%$; (m) $\mathrm{CF} 3 \mathrm{COOH}$, $\mathrm{CH}_{2} \mathrm{Cl}_{2}, 0^{\circ} \mathrm{C}$; PhMe, $\Delta, 100 \%$; (n) $\mathrm{Ph}_{3} \mathrm{P}=\mathrm{CH}_{2}$, DIABLH, THF.

图式 6 Rapport 研究组的合成方法

Scheme 6 Synthesis by Rapport's group 
65 发生傅克反应关吗啡骨架 B 环得到化合物 66, 随后 脱茮基保护、上氰基和端烯被氧化切断合成化合物 67 , 再经一系列官能团转化即可合成吗啡(Scheme 7).

\subsection{Fuchs 研究组的合成方法}

1987 年, Fuchs 研究组 ${ }^{[27]}$ 利用串联的分子内加成-烷 基化反应作为合成吗啡的关键步骤. 该合成路线先用 Mitsunobu 反应连接两个片段 68, 69 得到醚化合物 70, 脱除 TBS 保护基、随后将醇氧化成羰基、DIBAL-H 还 原羰基得到构型翻转的环化反应前体 71. 在丁基锂作 用下发生锂交换随后发生分子内的加成一烷基化反应， 一步成功构建了吗啡的四环骨架和含芳环季碳中心. 末 端双键双着弪化反应、氧化切断为醛基合成化合物 73, 还 原胺化和保护胺基得到 74. 经 Swern 氧化、烯醇甲醚化、 再次保护由于上一步骤脱除保护基的胺基、消除成双键 和 DDQ 氧化得到双稀产物 77, 随后脱除氮上的保护基, 发生氮杂的 1,6-加成反应得到混合物 78 和 79. 化合物 78 可以经过双键异构化反应转化为 79, 之后 $\mathrm{NaBH}_{4}$ 还 原得到可待因, 去甲基化后合成得到吗啡(Scheme 8).

\subsection{Tius 研究组的合成方法}

1992 年, Tius 研究组 ${ }^{[28]}$ 首次以 Diels-Alder 反应作为 关键步骤合成吗啡类生物碱. 其将对苯二醌化合物 80 与 81 发生分子间的 Diels-Alder 反应得到化合物 82. 硒
基环化氧化消除得到的氧负离子进攻亚胺离子、酸性条 件下缩酮去保护、Davis 试剂氧化羰基 $\alpha$ 位得差基后还 原消除成双键, Swern 氧化羟基得到 85. 路易斯酸作用 下芳环芳构化形成化合物 86. 硒基加成氧化消除、 $\mathrm{NaBH}_{4}$ 立体选择性还原、甲基锂脱保护然后还原胺化、 Dess-Martin 氧化烯丙醇得到 $\mathbf{8 8}$, 锌粉还原断开胺缩酮 并 Michael 加成环化、还原羰基并酸化得到化合物 90, 其后的合成采用 Gates 的合成路线(Scheme 9).

\subsection{Parker 研究组的合成方法}

1992 年, Parker 课题小组 ${ }^{[29,30]}$ 以芳基溴的自由基环 化反应作为关键步骤仅用 11 步就合成了消旋的二氢可 待因, 完成了可待因和吗啡的形式全合成. 在该合成路 线中, 经 Birch 还原, 一系列官能团转化以及 CBS 催化 的不对称还原后得到的化合物 91 经间氯过氧苯甲酸 ( $m$-CPBA) 的氧化后得到环氧化合物 92 , 化合物 92 在路 易斯酸的作用下环氧开环并用叔丁基二甲基硅烷基 (TBDMS)保护基保护得到化合物 93, 化合物 93 和化合 物 94 经一步 Mitsunobu 反应随后脱去硅基保护得到进 行关键步骤自由基环化反应的前体 95. 化合物 95 经自 由基引发剂偶氮二异丁腈( $\mathrm{AIBN}$ )和 $\mathrm{Bu}_{3} \mathrm{SnH}$ 作用后经历 一系列自由基环化/消除等过程一步构建了 $\mathrm{ABCE}$ 的吗 啡环系统得到化合物 96, 化合物 96 在 Birch 还原的条件

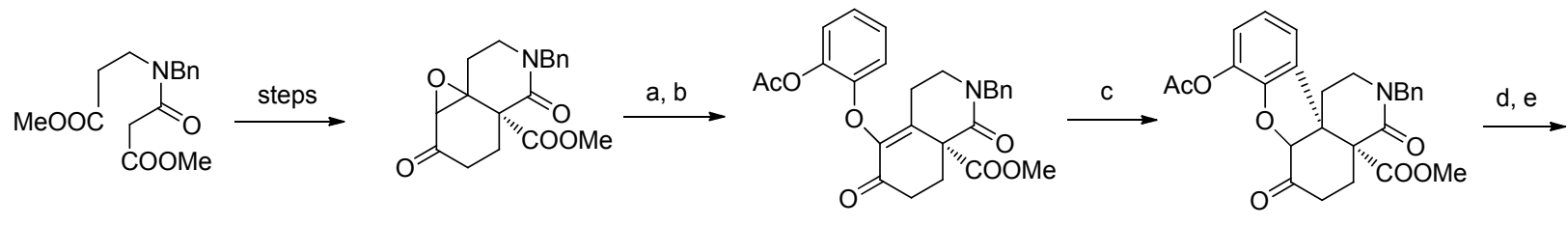

58<smiles>COC(=O)C1(OC)CC[C@@]2(C)C(=O)N(Cc3ccccc3)CC[C@@]12c1cccc(OC)c1OC</smiles>

62

59

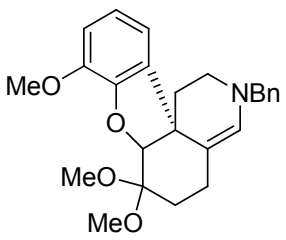

63

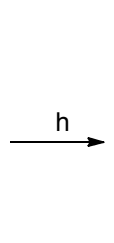

60
61

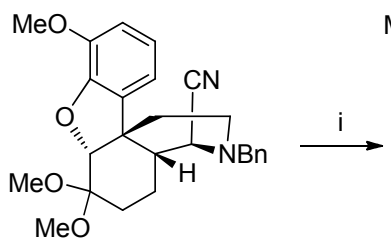

64

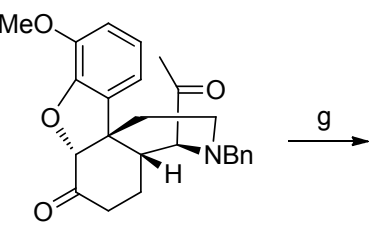

65

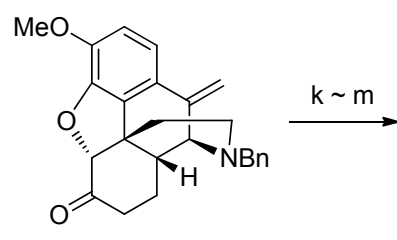

66

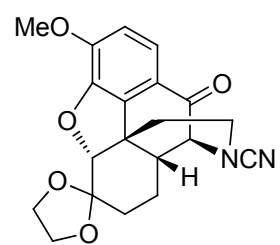

67

Reagents and conditions: (a) $\mathrm{KH}, \mathrm{THF}, 2-\mathrm{HOC}_{6} \mathrm{H}_{4} \mathrm{OCH}_{2} \mathrm{OMe}, 59 \%$; (b) $\mathrm{HOAc}, \mathrm{H}_{2} \mathrm{O}, \mathrm{THF} / \Delta ; \mathrm{Ac} 2 \mathrm{O}, \mathrm{Py}, 92 \%$; (c) hv, $\mathrm{PhH}, \mathrm{HOAc}, \mathrm{MeOH}, 99 \%$; (d) $\mathrm{HC}(\mathrm{OMe})_{3}, \mathrm{H}_{2} \mathrm{SO}_{4}, \Delta, 74 \%$; (e) $\mathrm{K}_{2} \mathrm{CO}_{3}, \mathrm{Mel}, \mathrm{Me}_{2} \mathrm{CO}, \Delta, 96 \%$; (f) $\mathrm{NaH}, \mathrm{EtSH}, \mathrm{DMF}, 90 \%$; (g) $i-\mathrm{Bu}_{2} \mathrm{AlH}, 98 \%$; (h) $\mathrm{HClO}$, $\mathrm{MeOH} ; \mathrm{KCN}$, $78 \%$; (i) MeLi, $4 \mathrm{~N} \mathrm{H}_{2} \mathrm{SO}_{4}, 99 \%$; (j) $\mathrm{TfOH}, 57 \%$; (k) TsOH, $\left(\mathrm{CH}_{2} \mathrm{OH}\right)_{2}$; (l) $\mathrm{BrCN}$; (m) $\mathrm{OsO}_{4}, \mathrm{NalO}_{4}, 74 \%$ three steps.

图式 7 Schultz 研究组的合成方法

Scheme 7 Synthesis by Schultz's group 


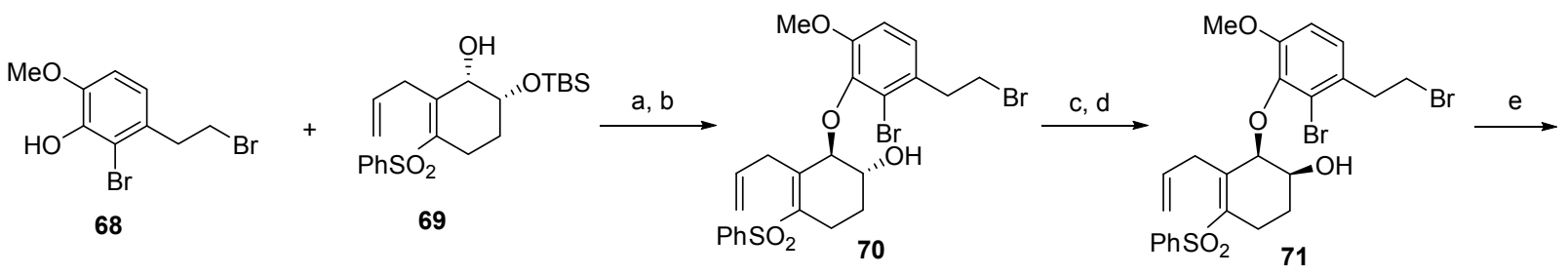<smiles></smiles>

72

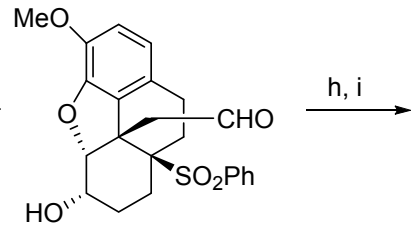

73

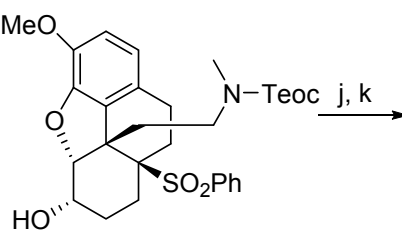

74<smiles>COC1=CCC(O)(c2ccccc2)C2(CCN(C)C(=O)OCc3ccccc3)Cc3ccc(OC)c1c3O2</smiles>

75<smiles>COC1=CC=C2CC[C@H]1Oc1c(OC)ccc3c1C23CCN(C)C(=O)O</smiles>

76

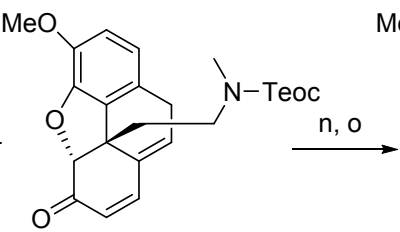

77

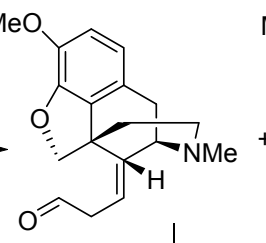

78

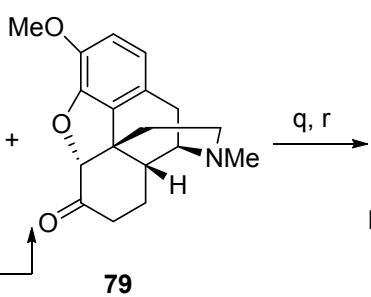<smiles>CN1CCC23c4c(ccc(O)c4[C@H](O)C2C1)CCN3C</smiles>

1 L-Morphine

Reagents and conditions:(a) $n$ - $\mathrm{Bu}_{3} \mathrm{P} / \mathrm{DEAD} / \mathrm{THF}, 85 \%$; (b) $48 \% \mathrm{HF} / \mathrm{CH}_{3} \mathrm{CN}, 95 \%$; (c) $\left(\mathrm{CrO}_{3} / \mathrm{aq} . \mathrm{H}_{2} \mathrm{SO}_{4}\right) /\left(\mathrm{CH}_{3}\right)_{2} \mathrm{CO}, 0{ }^{\circ} \mathrm{C}$; (d) $i-\mathrm{Bu}_{2} \mathrm{AlH} / \mathrm{THF},-78$ ${ }^{\circ} \mathrm{C}$ to $25{ }^{\circ} \mathrm{C}$; (e) n-BuLi, THF, $-78{ }^{\circ} \mathrm{C}$; (f) cat. OsO $/ \mathrm{NMO} / \mathrm{aq}$. $\left(\mathrm{CH}_{3}\right)_{2} \mathrm{CO}$; (g) Pb(OAc) $/ \mathrm{CHCl}_{3}, 85 \%$ two steps; (h) $\mathrm{CH}_{3} \mathrm{NH}_{2} \bullet \mathrm{HCl}^{\circ} \mathrm{CH}_{3} \cdot \mathrm{O}$ $\mathrm{H} / \mathrm{NaBH}_{3} \mathrm{CN}$; (i) $\mathrm{TeocCl} / \mathrm{CH}_{2} \mathrm{Cl}_{2} /$ aq. $\mathrm{NaHCO}_{3}, 85 \%$ two steps; (j) $\mathrm{Me}_{2} \mathrm{SO} / \mathrm{TFAA} / \mathrm{CH}_{2} \mathrm{Cl}_{2}$, then (Et) ${ }_{3} \mathrm{~N}$, $-78{ }^{\circ} \mathrm{C}$ to $20{ }^{\circ} \mathrm{C}, 95 \%$; (k) $\left(\mathrm{CH}_{3} \mathrm{O}\right)_{3} \mathrm{CH} / \mathrm{CH}_{3} \mathrm{OH} / \mathrm{TsOH}, 65^{\circ} \mathrm{C}$, then $\left(\mathrm{CH}_{3}\right)_{3} \mathrm{SiCH}_{2} \mathrm{OCOCl} / \mathrm{CH}_{2} \mathrm{Cl}_{2} / \mathrm{aq}$. $\mathrm{NaHCO}_{3}, 80 \%$; (I) $\left(\mathrm{CH}_{3}\right)_{3} \mathrm{COK} / \mathrm{THF}, 85 \%$; $(\mathrm{m}) \mathrm{DDQ} / \mathrm{TsOH} / \mathrm{CHCl} / \mathrm{H}_{2} \mathrm{O}$, $40 \%$; (n) $\mathrm{CF}_{3} \mathrm{COOH}, 90 \%$; (p) $\mathrm{CHCl}_{3} /$ aq. $\mathrm{NaHCO}_{3}, 60 \%$; (q) $\mathrm{HCl} /(\mathrm{Et})_{2} \mathrm{O} / \mathrm{CH}_{2} \mathrm{Cl}_{2}$, then $0.2 \mathrm{~mol} / \mathrm{L} \mathrm{NaOH} / \mathrm{CHCl}_{3}, 95 \%$; (r) $\mathrm{NaBH}_{4} / \mathrm{CH}_{3} \mathrm{OH}, 95 \%$; (s) $\mathrm{BBr}_{3} / \mathrm{CHCl}_{3}$

图式 8 Fuchs 研究组的合成方法

Scheme 8 Synthesis by Fuchs's group<smiles>C=CC1=CCC2(CC1)OCCO2</smiles>

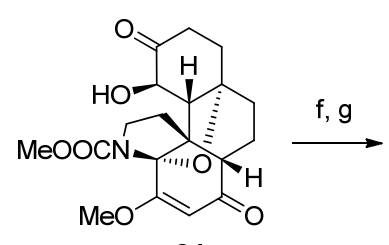

84

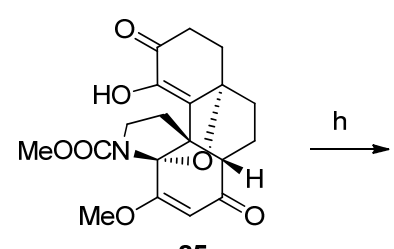

85

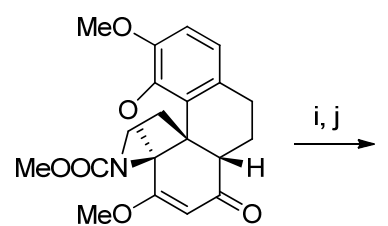

86

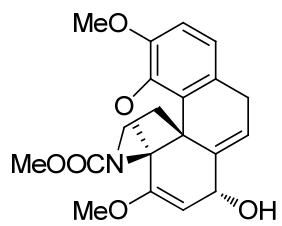

87

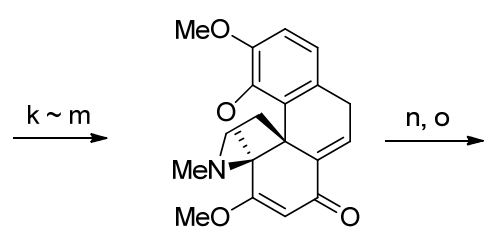

88

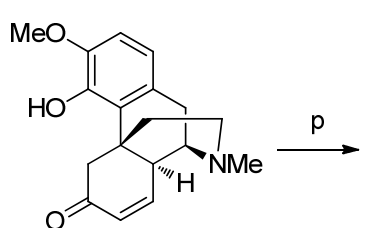

89<smiles>COc1ccc2c(c1O)[C@@]13CC(=O)C=C[C@H]1[C@@H](C2)N3C</smiles>

90 Thebainone-A

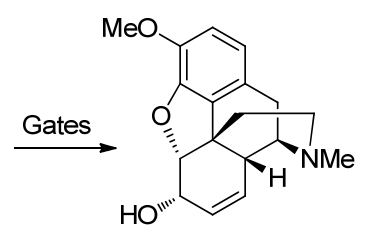

2 Codeine

Reagents and conditions: (a) PhMe, $100^{\circ} \mathrm{C}, 86 \%$; (b) $\mathrm{PhSeCl}, \mathrm{MeOH} ; \mathrm{H}_{2} \mathrm{O}_{2}, \mathrm{THF}, 80 \%$; (c) $\mathrm{H}_{3} \mathrm{O}^{+}, \mathrm{THF}, 90 \%$; (d) (Me $\mathrm{TH}_{2} \mathrm{NK}, \mathrm{Davis}$ oxazolidine, 70\% 88\%; (e) $\mathrm{H}_{2}, \mathrm{Pd} / \mathrm{C}$, THF, 75\%; (f) $\left(\mathrm{CF}_{3} \mathrm{CO}\right)_{2} \mathrm{O}, \mathrm{Me}_{2} \mathrm{SO},-78{ }^{\circ} \mathrm{C}$; (g) $\mathrm{Et}_{3} \mathrm{~N}, 23{ }^{\circ} \mathrm{C}$; (h) $\mathrm{BF}_{3}{ }^{\circ} \mathrm{Et}_{2} \mathrm{O}$; $\mathrm{K}_{2} \mathrm{CO}_{3}, \mathrm{Mel}$, $\mathrm{Me}_{2} \mathrm{CO}, 56 \%$ three steps; (i) PhSeCl, EtOAc; $\mathrm{H}_{2} \mathrm{O}_{2}$, THF, 70\%; (j) $\mathrm{NaBH}_{4}, \mathrm{MeOH}$; (k) MeLi, THF; (I) $\mathrm{HCHO}, \mathrm{NaBH}_{3} \mathrm{CN}, \mathrm{H}_{2} \mathrm{O}, \mathrm{MeCN}$ $54 \%$ three steps; (m) DMP, 75\%; (n) $\mathrm{Zn}, \mathrm{NH}_{4} \mathrm{Cl}, \mathrm{H}_{2} \mathrm{O}$, EtOH, 73\%; (o) $\mathrm{i}-\mathrm{Bu}_{2} \mathrm{AlH}$; $\mathrm{H}_{3} \mathrm{O}^{+}, 100 \%$; (p) $\mathrm{HOAc}^{\circ} 100^{\circ} \mathrm{C}, 67 \%$.

图式 9 Tius 研究组的合成方法

Scheme 9 Synthesis by Tius's group 
下氢胺化构筑了 D 环, 最后经 Swern 氧化以 $75 \%$ ee 值 得到二氢可待因酮 40 [(-)-dihydrocodeinone]. 该路线 共用 11 步，总收率为 $11.1 \%$ (Scheme 10).

\subsection{Overman 研究组的合成方法}

Heck 反应至 1972 年被美国化学家理查德・赫克发 现以来, 其无疑是受到最多合成化学家青睐的有效形成 新 $\mathrm{C}-\mathrm{C}$ 键的合成方法, 因此, Heck 反应在天然产物吗 啡的全合成中也得到了广泛的运用. 在 1993 年, Overman 课题小组 ${ }^{[31]}$ 通过一步钯催化的 Heck 反应快速地构 建了天然产物吗啡中含芳环的季碳手性中心, 之后再经 一步环氧开环构筑二氢呋喃环, 最终以 $1.9 \%$ 的收率, 共
用 14 步合成二氢可待因酮(Dihydrocodeinone) (Scheme 11).

\subsection{Mulzer 研究组的合成方法}

1998 年, Mulzer 等 ${ }^{[32]}$ 利用 Robinson 环化合成吗啡骨 架 $\mathrm{C}$ 环得到化合物 104, 之后用格式试剂的 Michael 加 成反应成功构筑含芳环的季碳手性中心，再在羰基 $\alpha$ 位 上溴合成化合物 105 . 分子内的亲核取代反应合成吗啡 骨架 $\mathrm{E}$ 环得到化合物 106. 随后发生脱卤反应，端烯硼 氢化氧化, 取代反应等一系列转化合成二氢可待因酮 (Scheme 12).<smiles>CN([AsH2])CCC1=C[C@H](O)CCC1</smiles>

91

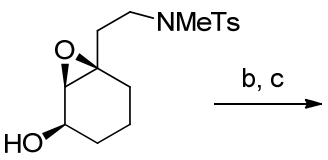

92<smiles>CCCCCCC1=CCC[C@@H](OCCCC)C1O</smiles>

93

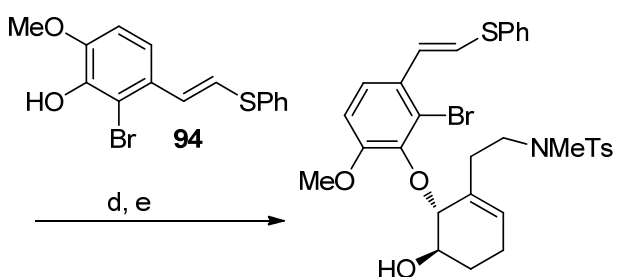

95

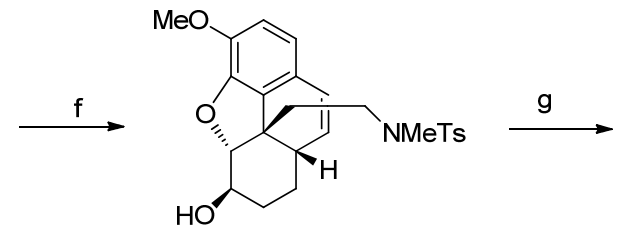

96<smiles>COc1ccc2c3c1O[C@H]1C(O)CC[C@H](C2)C31C</smiles>

97 (-)-dihydroisocodeine

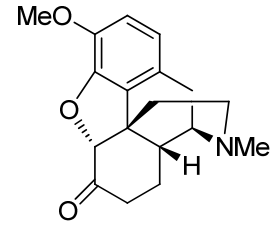

40 (-)-dihydrocodeine

Reagents and conditions: (a) $m$-CPBA, $\mathrm{CH}_{2} \mathrm{Cl}_{2}, 86 \%$; (b) Ti(Oi-Pr) $)_{4}$, benzene; (c) TBDMSOTf, $i-\mathrm{Pr}_{2} \mathrm{NEt} \mathrm{CH}_{2} \mathrm{Cl}_{2}, 61 \%$ two steps; (d) 94, $\mathrm{PBu}$, DEAD, THF; (e) $10 \% \mathrm{HF} / \mathrm{CH}_{3} \mathrm{CN}, 65 \%$; (f) $\mathrm{Bu}_{3} \mathrm{SnH}$, AlBN, benzene, $130{ }^{\circ} \mathrm{C}$ in a sealed tube, $30 \%$; (g) $\mathrm{Li} / \mathrm{NH}_{3}, t-\mathrm{BuOH}, \mathrm{THF},-10{ }^{\circ} \mathrm{C}, 80 \%$; (h) Swern oxidation, $80 \%$

图式 10 Parker 研究组的合成方法

Scheme 10 Synthesis by Parker's group<smiles>COc1ccc(CC=O)c(I)c1Br</smiles>

98<smiles>CCCCCCCC1=CCCCC1SNCCc1ccccc1</smiles>

99<smiles>CC1(C)CCCCC1</smiles><smiles>COc1ccc(C[C@@H]2C3CCCC=C3CCN2[R16](=O)c2ccccc2)c(OC)c1OC</smiles>

100

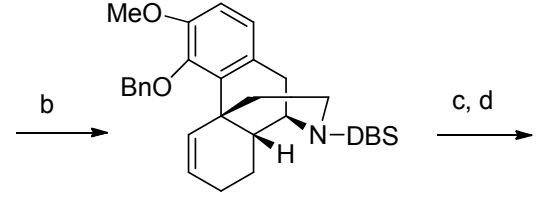

101

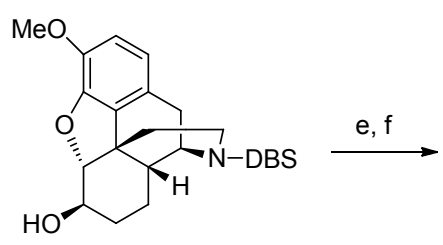

102<smiles>COc1ccc2c3c1O[C@H]1C(=O)CC[C@H](C2)[C@]31CCN</smiles>

40 dihydrocodeinone

Reagents and conditions:(a) $\mathrm{Znl}_{2}$, $\mathrm{EtOH}, 60{ }^{\circ} \mathrm{C}$; (b) $\left(\mathrm{Ph}_{3} \mathrm{P}\right)_{2} \mathrm{Pd}\left(\mathrm{OCOCF}_{3}\right)_{2}$, pentamethylpiperidine, $\mathrm{PhMe}, \Delta, 60 \%$; (c) $\mathrm{BF}{ }_{3} \bullet \mathrm{Et}_{2} \mathrm{O}, \mathrm{EtSH}, 79 \%$; (d) CSA, 3,5-( $\left.\mathrm{O}_{2} \mathrm{~N}\right)_{2} \mathrm{C}_{6} \mathrm{H}_{3} \mathrm{CO}_{3} \mathrm{H}, \mathrm{CH}_{2} \mathrm{Cl}_{2}, 60 \%$; (e) TRAP, NMO, 86\%; (f) $\mathrm{H}_{2}, \mathrm{Pd}(\mathrm{OH})_{2}, \mathrm{HCHO}, 90 \%$.

图式 11 Overman 研究组的合成方法

Scheme 11 Synthesis by Overman's group 
<smiles>COc1cc(Cl)c2c(c1OC)C(=O)CCC2</smiles>

103

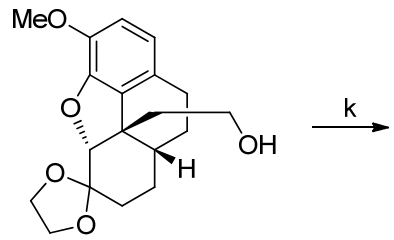

107<smiles>COc1cc(Cl)c2c(c1OC)C1=CC(=O)CC[C@H]1CC2</smiles>

104

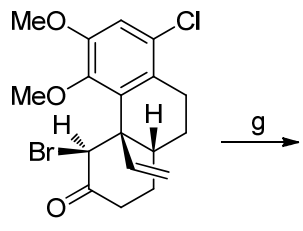

105

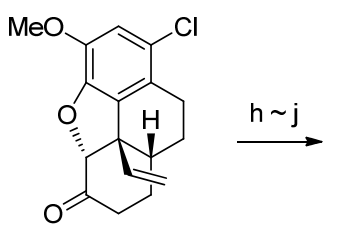

106

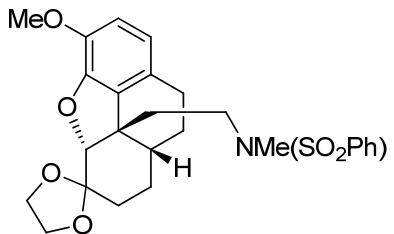

108

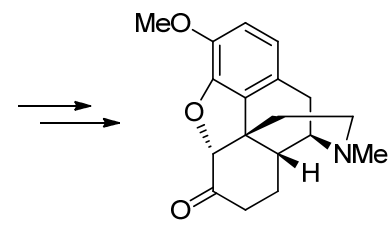

40 (-)-Dihydrocodeinone

Reagents and conditions: (a) $\mathrm{HCOOMe}, \mathrm{NaOMe}, \mathrm{C}_{6} \mathrm{H}_{6}, 95 \%$; (b) $\mathrm{MVK}, \mathrm{Et}_{3} \mathrm{~N}, \mathrm{MeOH}$; (c) $\mathrm{KOH}$, dioxane, $\mathrm{H}_{2} \mathrm{O}, 77 \%$ two steps; (d) $\left(\mathrm{H}_{2} \mathrm{C}=\mathrm{CH}\right)_{2} \mathrm{CuMgCl}$, THF, $-78 \sim 0^{\circ} \mathrm{C}$; (e) TMSCl, Et ${ }_{3} \mathrm{~N}, 0 \sim 25^{\circ} \mathrm{C}$; (f) NBS, THF, $-78{ }^{\circ} \mathrm{C}, 84 \%$ three steps; (g) DMF, $140{ }^{\circ} \mathrm{C}, 100 \%$; (h) TMSCl, $\left(\mathrm{CH}_{2} \mathrm{OH}\right)_{2}, \mathrm{CH}_{2} \mathrm{Cl}_{2}, 92 \%$; (i) $\mathrm{BH}_{3} \cdot \mathrm{Me}_{2} \mathrm{~S}$, THF, $\mathrm{H}_{2} \mathrm{O}_{2}, \mathrm{OH}^{-}, 70 \%$; (j) Ra-Ni, $\mathrm{MeOH}, \mathrm{KOH}, 98 \%$; (k) $\mathrm{PhSO}_{2} \mathrm{NHMe} \mathrm{ADDP}, \mathrm{Bu}_{3} \mathrm{P}, 81 \%$.

图式 12 Mulzer 研究组的合成方法

Scheme 12 Synthesis by Mulzer's group

\subsection{White 研究组的合成方法}

1999 年, White 小组 ${ }^{[33]}$ 也设计了合成吗啡的路线, 虽然最终与天然产物构型相反, 但在该路线中充分看出 其善用分子内反应合成天然产物的本领. 从异香兰素出 发, 依次经 Stobbe 缩合、分子内 Friedel-Crafts 反应、 Robinson 环化和分子内亲核取代反应构建了吗啡的 $\mathrm{ABCE}$ 四环骨架, 得到化合物 110. 保护差基, 随后制成 的酰氯和重氮甲烷反应得到卡宾前体 111, 在二价铑的 作用下构筑了含芳环的季碳手性中心. 化合物 113 在发 生贝克曼重排后合成了吗啡桥环 $\mathrm{D}$ 环, 再多次转化后得 到了右旋的可待因, 因与天然产物构型恰好相反, 所以 该合成是能算是一个形式合成(Scheme 13).

\subsection{Cheng 研究组的合成方法}

2000 年, Cheng 课题组 ${ }^{[34]}$ 采用钯催化环化和 Stevens 重排作为关键步骤合成吗啡. 从四氧异喹啉衍生物 116 经甲基化、 $\mathrm{NaBH}_{4}$ 还原、甲酸乙酷保护氮、二级醇去保 护得到醇 117, 随后经过 Mitsunobu 反应得到芳基酸 118 . 还原苯甲醛并硅梄保护得到化合物 119 , 发生分子内 Heck 反应构建吗啡骨架中二氢呋喃环, 得到化合物 120. 化合物 120 脱除硅基保护基并氯代得到化合物 121, 之后钯催化的环化反应得到 7 元环的产物 122. 苯 基锂作用下的甲基季按盐产物发生 Stevens 重排得到最 终产物 123. 该合成路线虽没最终合成吗啡, 但钯催化 环化和 Stevens 重排合成吗啡骨架 B 环的过程确实十分 新颖(Scheme 14).<smiles>COc1ccc(C=O)cc1O</smiles>
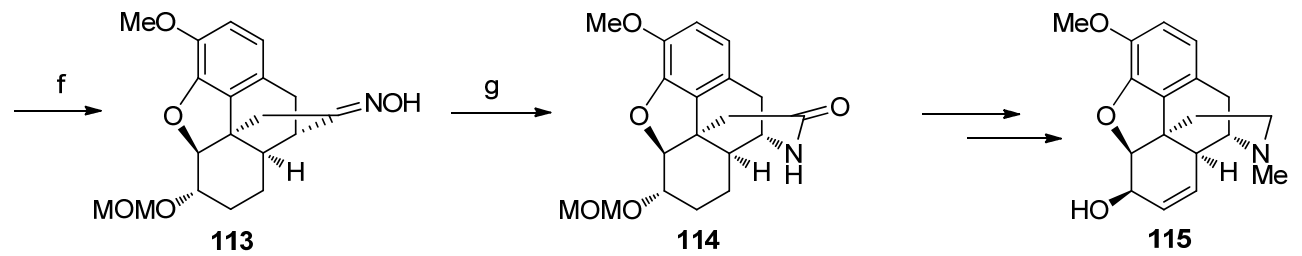

Reagents and conditions: (a) $\mathrm{CH}_{2}(\mathrm{OMe})_{2}, \mathrm{P}_{2} \mathrm{O}_{5}, \mathrm{CHCl}_{3}, 80 \%$; (b) $\mathrm{LiOH}$, THF/ $\mathrm{H}_{2} \mathrm{O}, 99 \%$; (c) (COCl) $)_{2}, \mathrm{C}_{6} \mathrm{H}_{6}$; (d) $\mathrm{CH}_{2} \mathrm{~N}_{2}, 63 \%$ two steps; (e) $\mathrm{Rh}_{2}(\text { acam })_{4}, \mathrm{CH}_{2} \mathrm{Cl}_{2}, 50 \%$; (f) $\mathrm{H}_{2} \mathrm{NOH} \cdot \mathrm{HCl}, \mathrm{NaOAc}, \mathrm{MeOH}, 90 \%$; (g) $\mathrm{AcOH}$, r.t., $62 \%$.

图式 13 White 研究组的合成方法

Scheme 13 Synthesis by White's group 
<smiles>CC(=O)OC1CCCc2cnccc21</smiles>

116

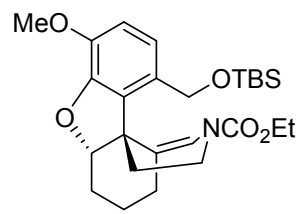

120<smiles>CCOC(=O)N1CCC2=C(CCCC2O)C1</smiles>

117

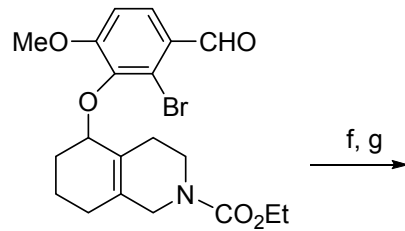

118<smiles>CCOC(=O)N1CCC2=C(CCCC2Oc2c(OC)ccc(OCC)c2Br)C1</smiles>

119

Reagents and conditions: (a) Mel, DCM, r.t. (b) $\mathrm{NaBH}_{4}, \mathrm{MeOH}$; (c) $\mathrm{ClCO}_{2} \mathrm{Et}, \mathrm{KHCO}_{3}$. DCE; (d) $\mathrm{NaOH}, \mathrm{MeOH}, 73 \%$ four steps; (e) 2-bromoisovanillin, DEAD, $\mathrm{Bu}_{3} \mathrm{P}$, THF, 85\%; (f) $\mathrm{NaBH}_{4}, \mathrm{MeOH}$; (g) TBSCl, imidazole, $85 \%$ two steps; (h) $\mathrm{Pd}(\mathrm{OAc})_{2} \bullet \mathrm{PPh}_{3}, \mathrm{Et}_{3} \mathrm{~N}, \mathrm{MeCN}, 67 \%$; (i) TBAF, THF; (j) NCS, $\mathrm{PPh}_{3}, 91 \%$ two steps; (k) $\mathrm{Pd}\left(\mathrm{PPh}_{3}\right)_{4}, \mathrm{Et}_{3} \mathrm{~N}, \mathrm{MeCN}$, 59\%; (I) Mel, DCM; (m) PhLi, Et ${ }_{2} \mathrm{O}, 83 \%$.

图式 14 Cheng 研究组的合成方法

Scheme 14 Synthesis by Cheng's group

\subsection{Ogasawara 研究组的合成方法}

2000 年, Ogasawara 研究组 ${ }^{[35]}$ 从化合物 124 出发通 过自由基环化反应构筑了含芳环季碳手性中心, 随后经 还原切断内酯、选择性保护伯醇和仲醇消除成双键得到 化合物 125. 化合物 125 在 Sakurai 条件下与烯丙基三甲 基硅反应生成化合物 126. 羰基乙二醇保护和氧化切断 端烯成醛, 之后发生傅克反应构建吗啡骨架 B 环, 得到 化合物 128. 经还原去保护, Mitsunobu 条件下伯醇转化 为化合物 129, 利用 Parker 路线中自由基环化合成吗啡 桥环 D 环. 整个路线从化合物 124 到 Gates 中间体共用 23 步, 总收率 $0.8 \%$ (Scheme 15).
Ogasawara 等 ${ }^{[36]} 2001$ 年报道了其另一条合成吗 啡的路线. 该路线利用光学纯化合物 131 与醚锂试剂反 应再经 PCC 氧化得到不饱和烯酮 132, 随后与乙稀基格 式试剂发生 1, 4-加成、 $N$-溴代琥珀酰亚胺(NBS)溴代、 $N, N$-二甲基甲酰胺(DMF)中加热得到二氧苯并呋喃化合 物, 用乙二醇保护羰基、喼氢化氧化、Piv 保护得到串 联环化反应前体 136. 化合物 136 在酸性条件下发生氧 鎓离子促进的关键步骤逆 Aldol 反应构建吗啡环. 还原 除去保护基、Mitsunobu 反应、锂氧条件下环化得到化 合物 139, 之后利用 Mulzer 的路线合成吗啡(Scheme 16).<smiles>COc1cccc(C2=CCCCC2O)c1OC</smiles>

128

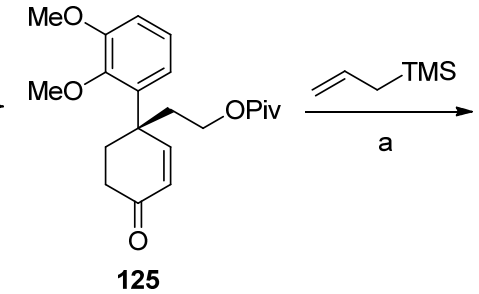

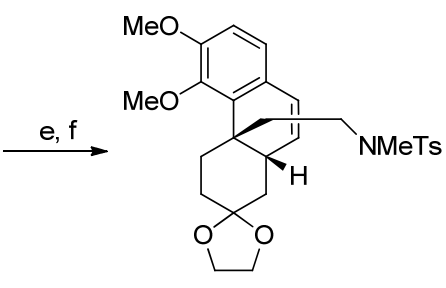

129<smiles>C=CCC1CC(=O)CCC1(CCO[PH](C)(C)C)c1cccc(OC)c1OC</smiles>

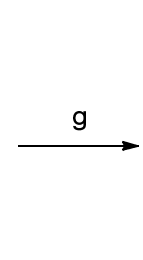

steps

130<smiles>COc1ccc2c(c1OC)C13CC(=O)CCC1CNCC2C3</smiles>

Gates' intermediate

图式 15 Ogasawara 研究组的合成方法

Scheme 15 Synthesis by Ogasawara's group 


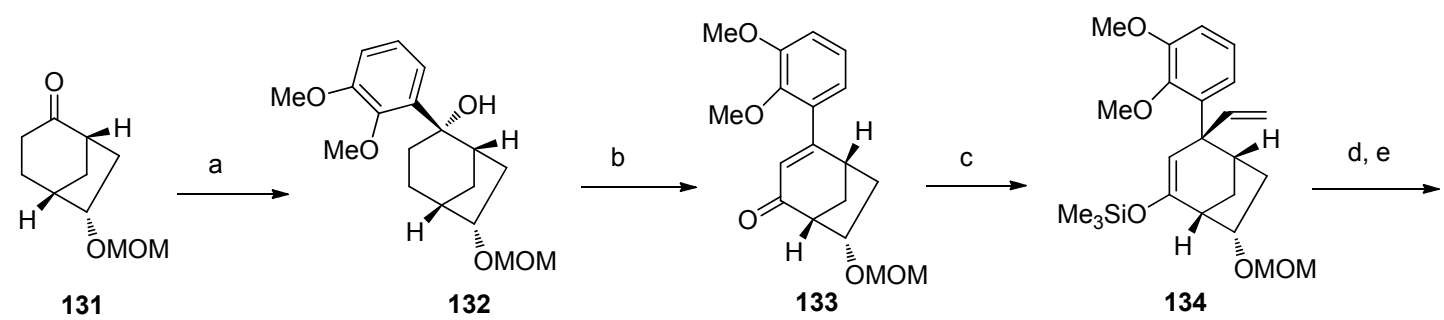

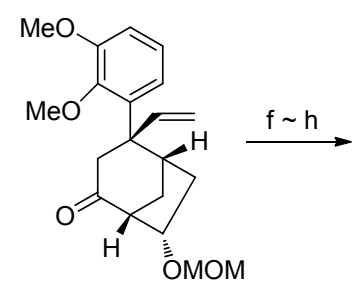

135

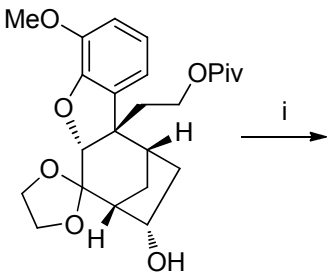

136

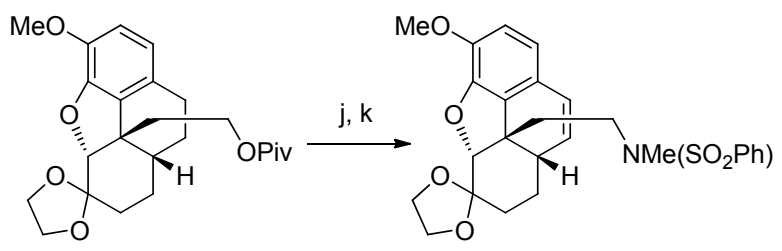

137
138

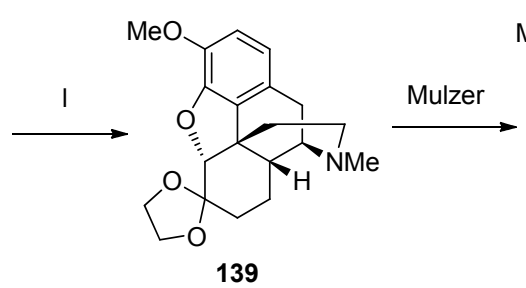

139

Reagents and conditions: (a) veratrole lithium; (b) PCC, $\mathrm{CH}_{2} \mathrm{Cl}_{2}, 81 \%$ two steps; (c) $\mathrm{CH}_{2}=\mathrm{CHMgCl}, \mathrm{CuBr} \cdot \mathrm{SMe}_{2}, \mathrm{Me}_{3} \mathrm{SiCl}, \mathrm{HMPA}, \mathrm{THF}, 75 \%$; (d) NBS, $\mathrm{CH}_{2} \mathrm{Cl}_{2}, 99 \%$; (e) DMF, $\Delta, 82 \%$; (f) $\left(\mathrm{CH}_{2} \mathrm{OSiMe}_{3}\right)_{2}, \mathrm{Me}_{3} \mathrm{SiOTf}, \mathrm{CH}_{2} \mathrm{Cl}_{2}, 71 \%$; (g) $\mathrm{BH}_{3}-\mathrm{Me}_{2} \mathrm{~S}$, then $30 \% \mathrm{H}_{2} \mathrm{O}_{2}, \mathrm{NaOH}, 72 \%$; (h) PivCl, Py, 87\%; (i) TsOH, $\left(\mathrm{CH}_{2} \mathrm{OH}\right)_{2}$, PhH, $\Delta, 85 \%$; (j) $\mathrm{LiAlH}_{4}, 100 \%$; (k) $\mathrm{PhSO}_{2} \mathrm{NHMe}, \mathrm{ADDP}, \mathrm{Bu} 3 \mathrm{P}, \mathrm{THF}, 78 \%$; (l) Li, $\mathrm{NH}_{3}, t-\mathrm{BuOH}, \mathrm{THF}, 70 \%$.

图式 16 Ogasawara 研究组的合成方法

Scheme 16 Synthesis by Ogasawara's group

\subsection{Taber 研究组的合成方法}

2002 年, Taber 等 ${ }^{[37]}$ 发表了吗啡的合成路线, 该路 线中的消旋化合物酮 $\mathbf{1 4 0}$ 与 $(S, S)$-二苯基乙二醇反应得 到非对映异构体 142 和 143, 这两种化合物可通过柱色 谱分离分开. 化合物 143 通过苄位的亲核取代反应和缩 酮水解得到化合物 144. 随后经立体选择性的还原羰 基、Mitsunobu 反应反转构型、还原叠氮化得到化合物 146, 引入烷基化得到关键中间体 147. 经臭氧切断反 应、碱性条件下发生分子内的烷基化和 Robinson 环化 得到不饱和酮 148, 一举构建了吗啡骨架的 $\mathrm{ABCD}$ 环. 后经还原和 $\mathrm{BBr}_{3}$ 脱除甲基生成二氢呋喃环产物 149. 继 而通过一系列转换得到吗啡(Scheme 17).

\subsection{Trost 研究组的合成方法}

2002 年, Trost 研究小组 ${ }^{[38,39]}$ 报道了以钯催化的不对 称烯丙基烷基化反应和 Heck 反应作为关键步骤不对称 合成可待因 $[(-)$-Codeine $]$ 的方法, 方法简单, 有效. 合 成路线中首先通过一步钯催化的不对称烯丙基烷基化 反应高效立体专一性地合成了芳基醚化合物 153 , 化合 物 153 在醛基被保护后, 酯基还原成伯醇, 经 Mitsunobu 反应生成氰基, 脱保护释放醛基成化合物 154 . 化合物 154 在经第一次 Heck 反应后成功构建了 $\mathrm{ACE}$ 三环得到
化合物 155, 化合物 155 经 Corey-Fucus 烯化反应后生成 烯基溴化合物 156. 随后化合物 $\mathbf{1 5 6}$ 通过第二次 Heck 反 应构筑了 B 环得到苯并二氢呋喃的骨架 157 , 之后经一 些简单氧化还原反应得到化合物 $\mathbf{1 6 0}$, 化合物 160 经一 步氢胺化反应构筑 $\mathrm{D}$ 环得到目标分子可待因. 该路线简 洁高效仅用了 15 步, 总收率 6.8\% (Scheme 18).

\subsection{Fukuyama 研究组的合成方法}

2006 年, Fukuyama 课题小组 ${ }^{[40]}$ 同样利用分子内的 Heck 反应作为合成可待因和吗啡的关键步骤. 该路线 先由碘代化合物 162 和环氧化合物 163 发生一步 Tsuji-Trost 反应形成醚键，随后用 Mitsunobu 反应翻转 仲醇的构型, 醇在与对硝基苯甲酸反应, 脱 TBS 保护, 伯醇转化为腈化合物 167. 化合物 167 还原脱去茮酯保 护、TBS 保护, 还原氰基再用氯甲酸甲酯保护氨基得关 键步骤 Heck 反应的前体 $\mathbf{1 6 8}$. 化合物 168 经 Heck 反应 一步成功高效地构筑了二氢呋喃环和含芳环的季碳手 性中心, TBS 保护基脱除后得到单一构型的化合物 169, 随后化合物 169 经过一步 Mannich 反应构筑 B, C 两环 完成了吗啡所有环系的建立, 之后经几步官能团的转化 和修饰最终共用 25 步, $6.7 \%$ 的总收率完成了消旋吗啡 (rac-Morphine)的全合成(Scheme 19). 


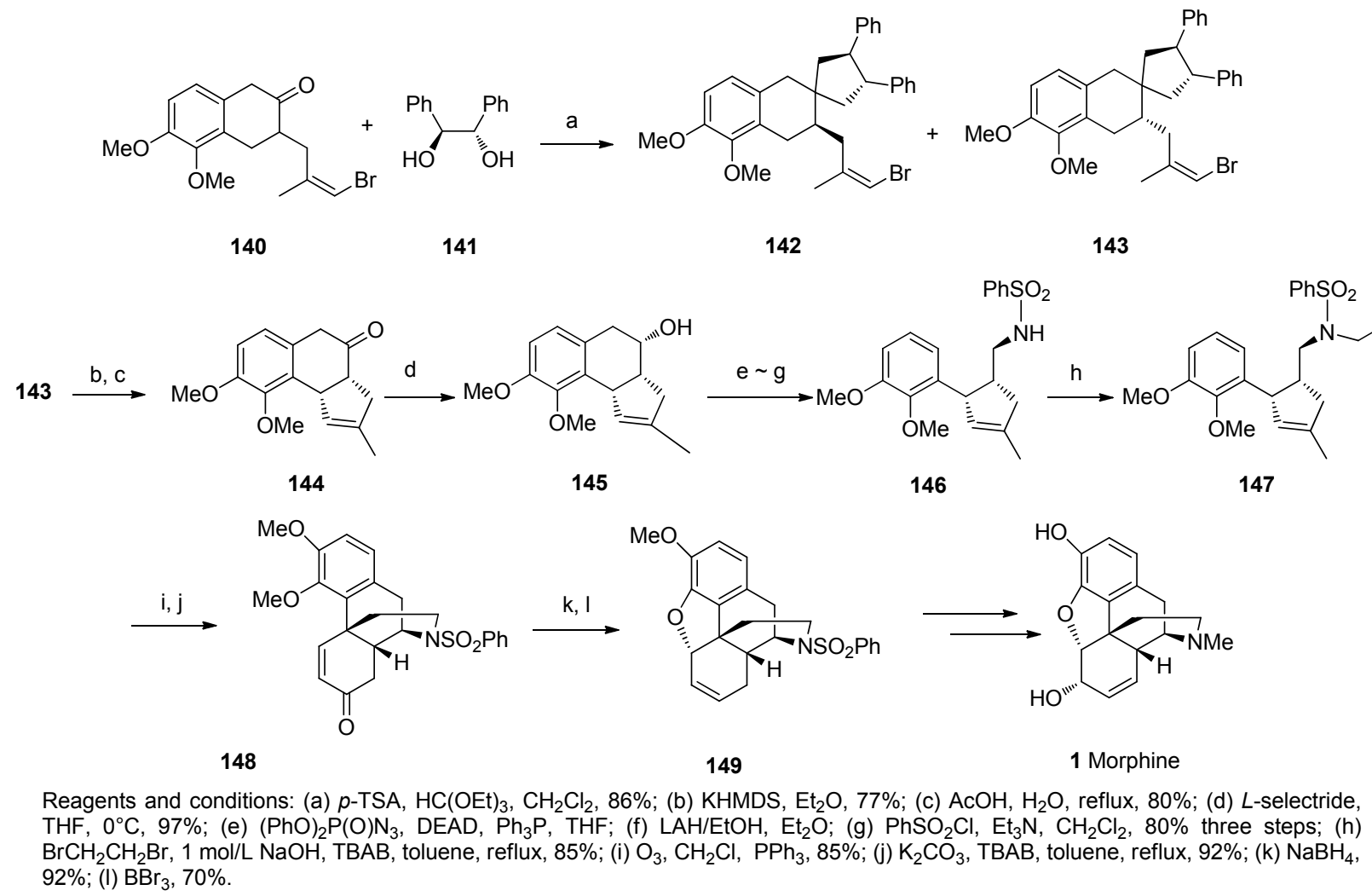

图式 17 Taber 研究组的合成方法

Scheme 17 Synthesis by Taber's group
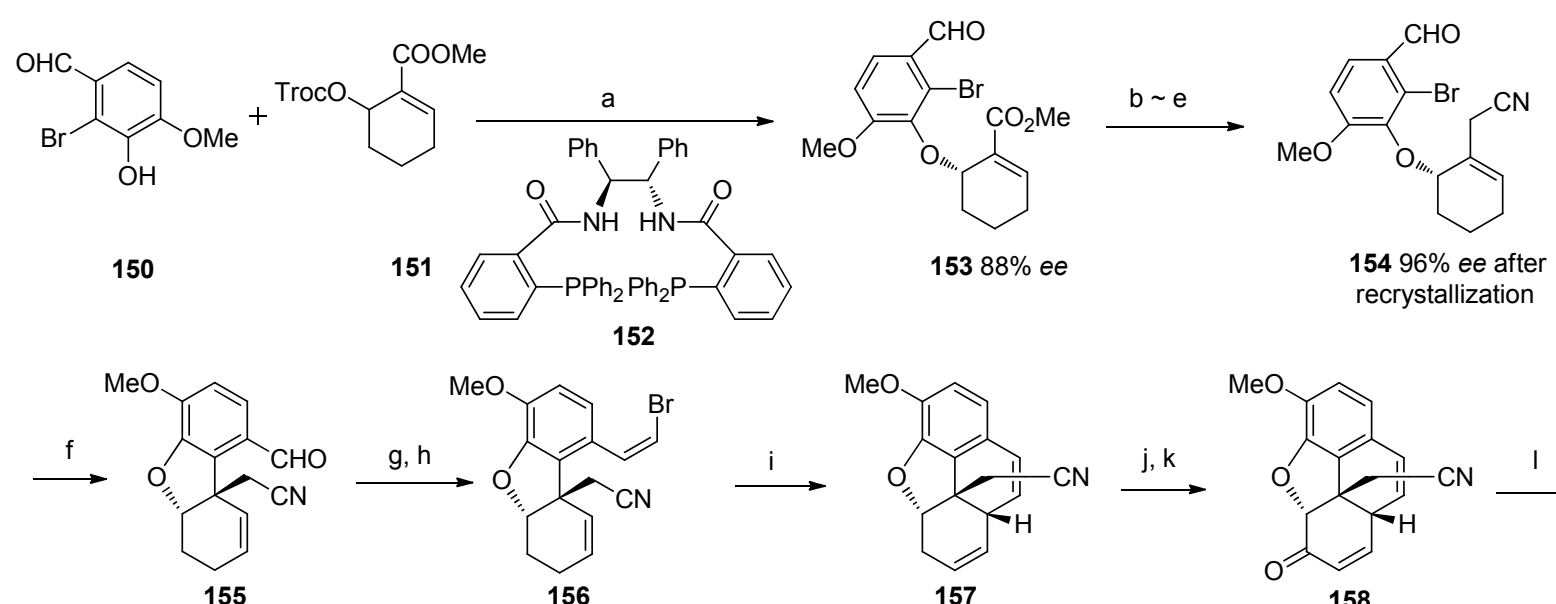

152

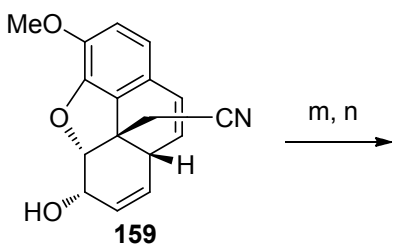<smiles>COc1ccc(/C=C\Br)c2c1O[C@H]1CCC=C[C@@]21CC#N</smiles>

156

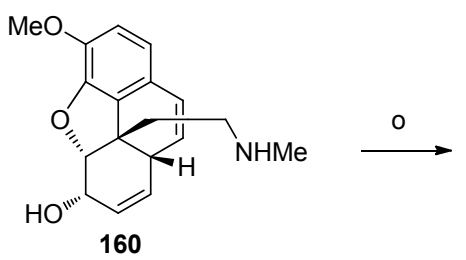

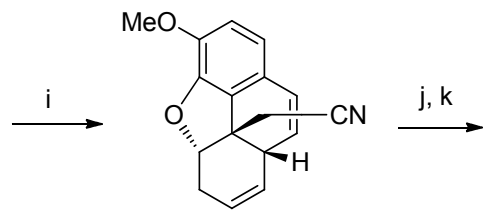

157

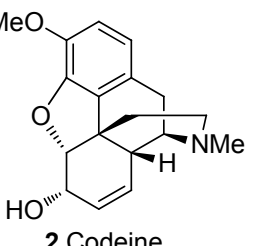

Reagents and conditions: (a) $\left[\left(\eta^{3}-\mathrm{C}_{3} \mathrm{H}_{5}\right) \mathrm{PdCl}\right]_{2}, \mathrm{NEt}_{3}, \mathrm{CH}_{2} \mathrm{Cl}_{2}, 152,72 \%$; (b) $\mathrm{TsOH}, \mathrm{CH}(\mathrm{OMe})_{3}, \mathrm{MeOH}$; (c) DIBALH, toluene; (d) acetonecyanohydrin, $\mathrm{Ph}_{3} \mathrm{P}$, DIAD, $\mathrm{Et}_{2} \mathrm{O}$; (e) TsOH, aq. THF, 65\% four steps; (f) $\mathrm{Pd}(\mathrm{OAc})_{2}$, dppp, $\mathrm{Ag}_{2} \mathrm{CO}_{3}$, toluene, $107^{\circ} \mathrm{C}, 91 \%$; (g) $\mathrm{CBr}_{4}$, $\mathrm{PPh}_{3}, \mathrm{CH}_{2} \mathrm{Cl}_{2}$; (h) $n$ - $\mathrm{Bu}_{3} \mathrm{SnH}, \mathrm{Pd}\left(\mathrm{PPh}_{3}\right)_{4}$, toluene, 80\%; (i) $\mathrm{Pd}(\mathrm{OAc})_{2}$, dppp, $\mathrm{Ag}_{2} \mathrm{CO}_{3}$, toluene, $65 \%$; (j) $\mathrm{SeO}_{2}, 1,4$-dioxane, $75{ }^{\circ} \mathrm{C}$; (k) $\mathrm{DMP}$, $58 \%$; (I) DIBALH, THF/Et $2 \mathrm{O}, 99 \%$; (m) DIBALH, THF/Et $2 \mathrm{O}$; (n) $\mathrm{NH}_{4} \mathrm{Br}, \mathrm{MeNH}_{2}, \mathrm{MeOH}$, then $\mathrm{NaBH}_{4}, 100 \%$; (o) LDA, Tungten bulb, THF, $57 \%$.

图式 18 Trost 研究组的合成方法

Scheme 18 Synthesis by Trost's group 


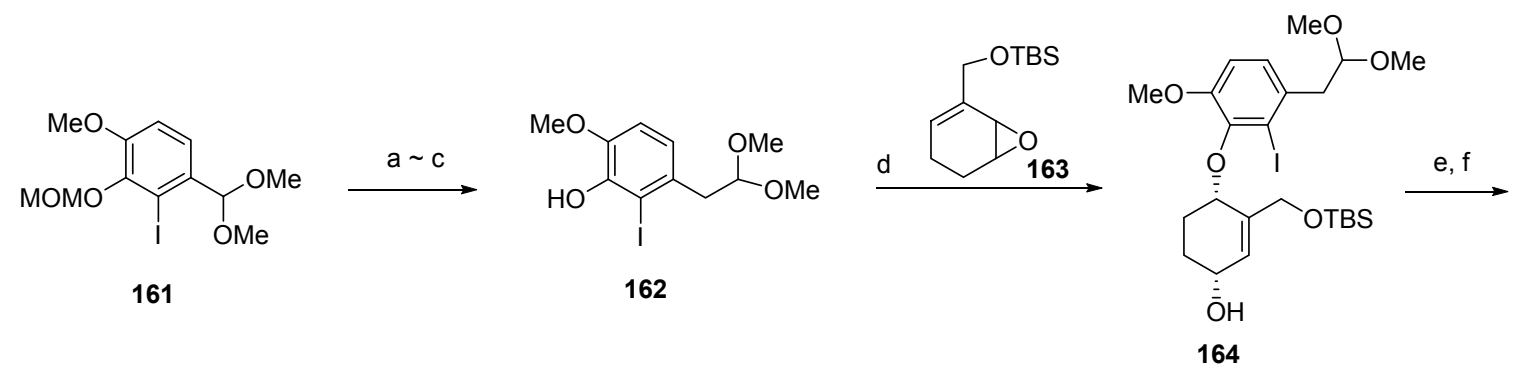<smiles>COc1ccc(CC(OC)OC)c(I)c1O[C@H]1CCC(OC(C)(C)O)C=C1CO</smiles>

165

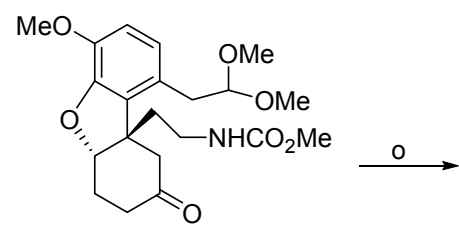

169

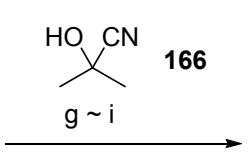<smiles>COc1ccc(CC(OC)OC)c(I)c1O[C@@H]1CC[C@@H](O)C=C1CC#N</smiles>

167

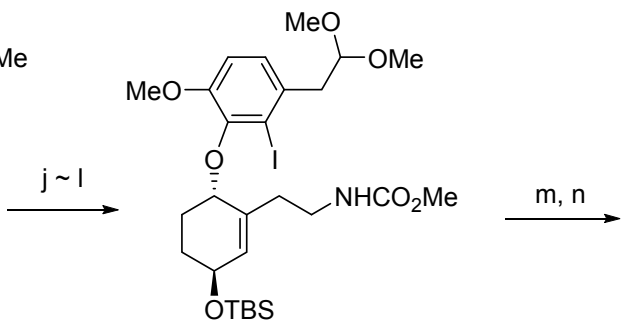

168

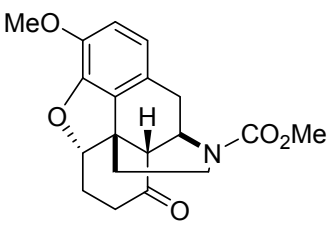

170

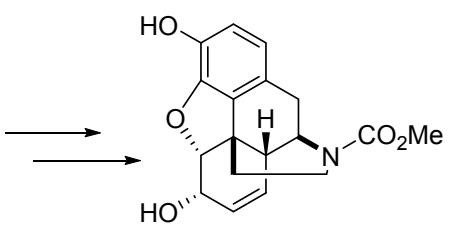

Morphine

Reagents and conditions: (a) AcOH, aq. THF; (b) $\mathrm{MeOCH}_{2} \mathrm{PPh}_{3} \mathrm{Cl}$, NaHMDS, THF; (c) $\mathrm{HCl}, \mathrm{MeOH}, 81 \%$ three steps; (d) 163 , $\mathrm{Pd}_{2}(\mathrm{dba})_{3}, \mathrm{P}(2 \text {-furyl })_{3}, \mathrm{MeCN}, 91 \%$; (e) p-nitrobenzoic acid, $\mathrm{PPh}_{3}$, DEAD; (f) CSA, MeOH, 85\% two steps; (g) 166, $\mathrm{PPh}_{3}, \mathrm{DEAD}$, toluene; (h) $\mathrm{LiBH}_{4}, \mathrm{Et}_{2} \mathrm{O}-\mathrm{MeOH}$; (i) TBSCl, imidazole, DMF, 91\% three steps; (j) DIBAL, DCM, $-78 .{ }^{\circ} \mathrm{C}$; (k) $\mathrm{NaBH}_{4}, \mathrm{MeOH}$; (l) $\mathrm{Cl}_{2} \mathrm{CO}_{2} \mathrm{Me}, \mathrm{K}_{2} \mathrm{CO}_{3}, 94 \%$ three steps; (m) $\mathrm{Pd}_{2}(\mathrm{dba})_{3}, \mathrm{P}(\text { o-tolyl })_{3}, \mathrm{NEt}_{3}, \mathrm{CH}_{3} \mathrm{CN}$; (n) TBAF, 87\%; (o) $\mathrm{HCl}, \mathrm{MeOH}$, reflux, $94 \%$.

图式 19 Fukuyama 研究组的合成方法

Scheme 19 Synthesis by Fukuyama's group

\subsection{Hudlicky 研究组的合成方法}

2007 年, Hudlicky 研究小组 ${ }^{[41]}$ 利用手性源化合物 172 作为反应原料, 通过 Mitsunobu 反应和 Heck 反应作 为合成的关键步骤构建二氢呋喃以及含芳环季碳手性 中心得到关键中间体 178, 而后再经过第二次的 Heck 反 应成功构建 B 环得到化合物 180, 最后在醋酸录的作用 下关上 $\mathrm{D}$ 环. 该路线共用 15 步, $0.23 \%$ 的总收率完成了 对映可待因(ent-Codeine)的全合成(Scheme 20).

\subsection{Chida 研究组的合成方法}

2008 年, Chida 课题小组 ${ }^{[2]}$ 报道了以一系列 Claisen 重排反应作为关键步骤的合成二氢可待因 (Dihydrocodeine) 的方法. 通过合成烯基三氟磺酸酯化 合物 189 和硼酸化合物 190 发生 Suzuki 反应得到偶联产 物, 并在二氯二氧基苯醌(DDQ)的作用下去除对甲氧基 芐基(PMP)保护基得到化合物 192, 接着脱叔丁基二甲 基硅基(TBS)的化合物 193 发生连续两次 Claisen 重排反 应构筑了含芳基季碳并得到化合物 194, 化合物 194 经
$m$-CPBA 制备环氧后环氧开环构建二氢呋喃环, 而后还 原酯基成醛发生傅克反应构筑 B 环, 再经 Birch 还原条 件下构筑 D 环. 合成路线共用 24 步, $3.8 \%$ 的总收率合成 了对映二氢化可待因 (rac-Dihydroisocodeine) (Scheme 21).

\subsection{Guillou 研究组的合成方法}

同年, Guillou 课题小组 ${ }^{[4]}$ 利用内酯开环的 Michael 加成反应和 Eschenmoser-Claisen 重排反应作为关键步 骤完成了可待因的全合成. 该合成路线首先通过一步酯 化得到化合物 201, 化合物 201 经 Heck 反应形成内酯化 合物 202, 化合物 202 再经氧化脱除双键形成 $\alpha, \beta$ 不饱和 酮化合物 203, 随后经过胺解, 还原酰胺得到化合物 205. 化合物 205 经一步 Eschenmoser-Claisen 重排反应 建立了正确立体构型的 $C(14)$. 接下来还原酰胺, 傅克 反应构建 C 环，再通过几步官能团转化经 Birch 还原条 件下构筑 D 环, 最后以 17 步, $0.64 \%$ 的总收率完成了可 待因的全合成(Scheme 22). 


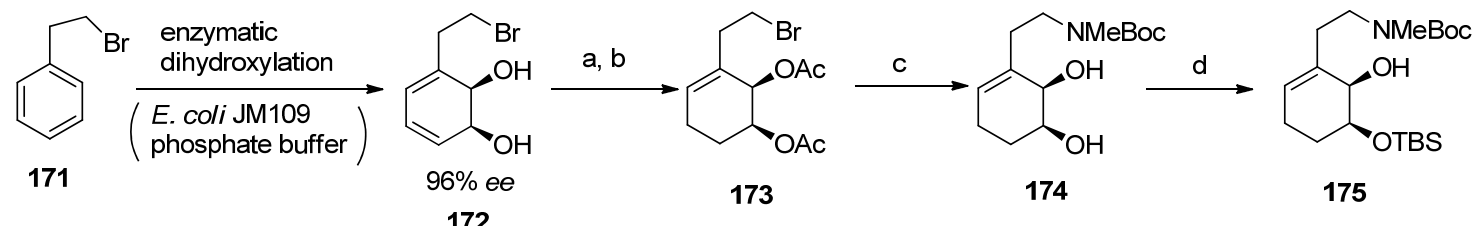

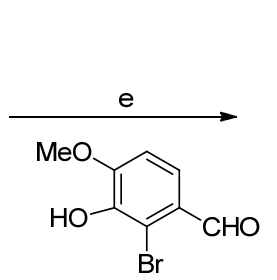

176

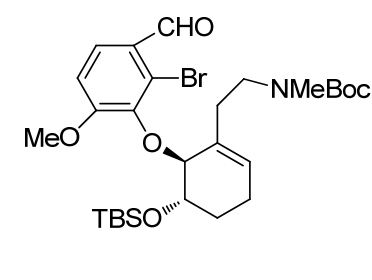

177
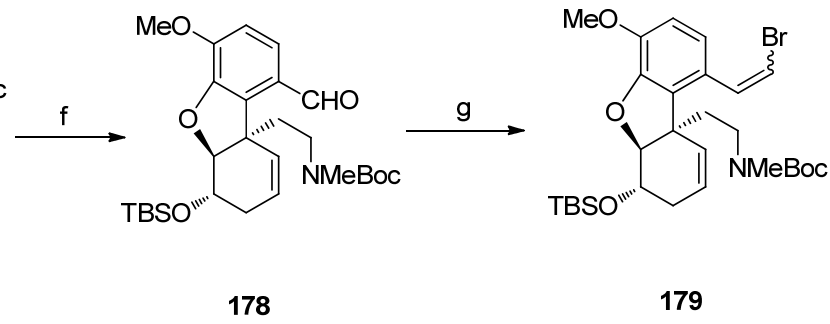

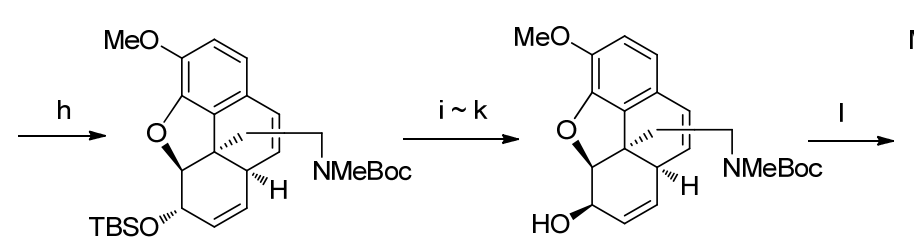

180

181

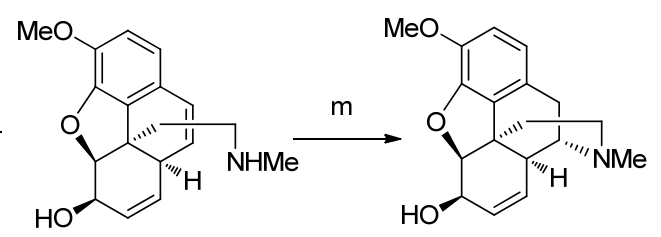

182

2 (+)-codeine

Reagents and conditions: (a) $\mathrm{KO}_{2} \mathrm{CN}=\mathrm{NCO}_{2} \mathrm{~K}, \mathrm{AcOH} / \mathrm{MeOH}$; (b) $\mathrm{Ac} \mathrm{C}_{2} \mathrm{O}, \mathrm{Et} 2 \mathrm{~N}, \mathrm{DMAP}, \mathrm{CH}_{2} \mathrm{Cl}_{2}, 47 \%$; (c) $\mathrm{MeNH}_{2}, \mathrm{~K}_{2} \mathrm{CO}_{3}$, THF, then $\mathrm{Boc} 2 \mathrm{O}$, DMAP, $\mathrm{CH}_{2} \mathrm{Cl}_{2}, 50 \%$; (d) TBSCl, imidazole, $\mathrm{CH}_{2} \mathrm{Cl}_{2}$; (e) 176, $\mathrm{Bu}_{3} \mathrm{P}$, DIAD, THF, 55\%; (f) $\mathrm{Pd}(\mathrm{OAc})_{2}, \mathrm{Ag}_{2} \mathrm{CO}_{3}$, dppf, toluene, 82\%; (g) $\mathrm{Ph}_{3} \mathrm{PCH}_{2} \mathrm{Br}_{2}, t$-BuOK, THF, 49\%; (h) $\mathrm{Pd}(\mathrm{OAc})_{2}, \mathrm{Ag}_{2} \mathrm{CO}_{3}$, dppp, toluene, 44\%; (i) TBAF, THF; (j) IBX, DMF; (k) $\mathrm{NaBH}_{4}, \mathrm{MeOH} 72 \%$; (I) TFA, $\mathrm{CH}_{2} \mathrm{Cl}_{2}, 88 \%$; (m) $\mathrm{Hg}(\mathrm{OAc})_{2}$, Et ${ }_{3} \mathrm{~N}$, THF, then $\mathrm{LiAlH}_{4}, 18 \%$.

图式 20 Hudlicky 研究组的合成方法

Scheme 20 Synthesis by Hudlicky's group

\subsection{Stork 研究组的合成方法}

2009 年 Stork 课题小组 ${ }^{[44]}$ 以苯并呋喃的 DA 环化反 应作为关键步骤一步构建了吗啡的 B 环和 C 环，最终完 成了吗啡的消旋合成. 合成路线从化合物 208 经多步反 应得到化合物 209. 化合物 209 和端醛化合物在 Schwartz 试剂的作用下反应得到仲醇化合物, 再经三乙 基硅醚(TES)保护得到 DA 反应前体化合物 211. 化合物 211 经过分子内的 DA 反应得到环化产物 $212 \alpha$ 和 $212 \beta$, 其中 $212 \alpha$ 为主要产物. 化合物 $212 \alpha$ 和 $212 \beta$ 经超氢(三 乙基硼氢化锂)还原, Dess-Martin (DMP)氧化成醛进行 Witting 反应得烯醇醚, 脱 TES 保护基, DMP 氧化成酮化 合物 213, 化合物 213 被还原成醇化合物并和甲基磺酰 氯反应生成甲基磺酸酯, 然后还原胺化成甲胺化合物 215. 最后 D 环的构筑由化合物 215 经过一步 $\mathrm{S}_{\mathrm{N}} 2$ 的取 代反应得到, 之后再经一系列官能团转化得到可待因. 该路线历经 22 步, 以 $2.0 \%$ 的总收率完成了消旋可待因 (rac-Codeine)的全合成(Scheme 23).

\subsection{Magnus 研究组的合成方法}

2009 年, Magnus 课题小组 ${ }^{[45]}$ 以苯酚烷基化反应为 关键步骤完成了可待因的消旋全合成. 该路线从芳基溴 化合物 217 和嗍酸化合物 $\mathbf{2 1 8}$ 出发经过一步 Suzuki 偶联
反应得到化合物 219 , 化合物 219 转化为溴代乙缩醛化 合物 220. 化合物 220 和 $\mathrm{CsF}$ 反应生成化合物 221 构筑 了含芳环的手性季碳. 化合物 221 经 Henry 反应脱水和 随后的 Michael 加成反应一步构建了吗啡的 ABC 三环 得到化合物 222. 化合物 222 经还原硝基烯得到化合物 223. 化合物 223 经 $\mathrm{LiAlH}_{4}$ 还原成醇化合物 224, 化合物 224 在酸性条件下还原胺化关上 D 环，与此同时二氢呋 喃环经酚羟基进攻烯丙基正离子关环得到，之后脱水得 到双键化合物 225, 此时吗啡的五环体系已经全部建立. 接下来氮上受酰基保护得化合物 $\mathbf{2 2 6}$ 到目标分子可待因 的转化过程皆与 Taber 等 ${ }^{[37]}$ 在 2002 年发表的吗啡全合 成路线相同. Magnus 课题小组的可待因消旋合成总收 率为 $20.1 \%$ ，总共用 13 步(Scheme 24).

\subsection{Metz 研究组的合成方法}

2011 年, Metz 课题组 ${ }^{[46]}$ 利用 1,3-偶极环加成作为关 键步骤完成了可待因的消旋全合成. 该合成从商品化原 料异香兰素出发, 通过酚羟基导向的苯环溴代，甲基化 作用和 Wittig 反应合成化合物 228. 化合物 228 经一步 Suzuki 偶联生成化合物 $\mathbf{2 3 0}$, 化合物 230 通过三氟醋酸 碘苯氧化苯酚随后脱去缩醛保护得到化合物 231, 化合 物 231 和硝酮进行 1,3 偶极环加成反应, 之后经 
<smiles>CC(=O)OC[C@H]1OC=C[C@H](OC(C)=O)[C@H]1OC(C)=O</smiles>

183

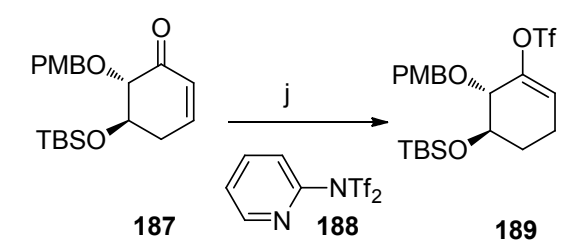

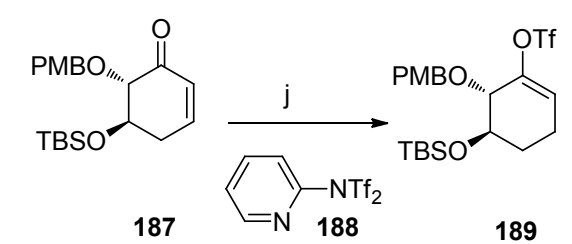

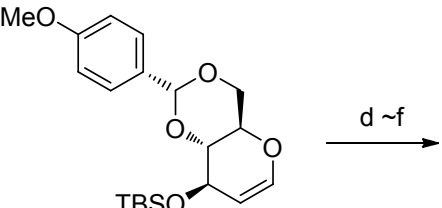

184<smiles>CO[C@H]1C[C@@H](O[R16](C)(C)C)[C@H](CI)O[C@H]1CI</smiles>

185<smiles>C=C1O[C@H](OC)C[C@H](OC(C)C)[C@@H]1OCCCC</smiles>

186<smiles>COc1cccc(Br)c1OC</smiles>

189<smiles>COc1cccc(C2=CCC[C@@H](OCC(C)C)[C@H]2OC)c1OC</smiles>

191<smiles>COc1cccc(C2=CCCC(OC(C)C)C2O)c1OC</smiles>

192<smiles>COc1cccc(C2=CCC[C@@H](O)[C@H]2O)c1OC</smiles>

193<smiles>CCOC(=O)C[C@H]1CCC=C[C@]1(CC(=O)OCC)c1cccc(OC)c1OC</smiles>

194<smiles>CCOC(=O)CC1CC[C@H](OC(C)C)[C@H]2Oc3c(OC)cccc3[C@]12CC(=O)OCC</smiles>

195

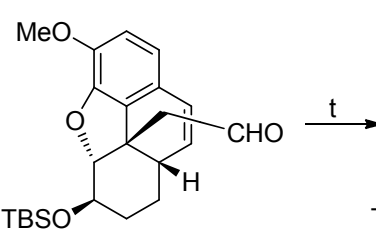

197

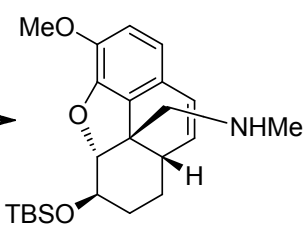

198

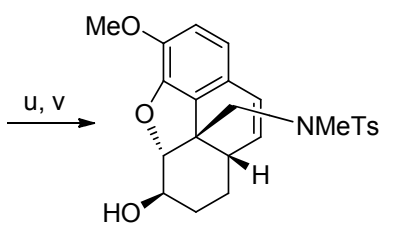

199<smiles>COc1cccc2c1O[C@H]1[C@@H](OC(C)(C)C)CC[C@H](CC=O)[C@@]21CC=O</smiles>

196

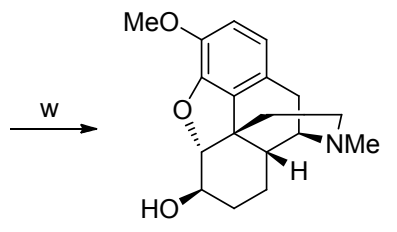

200

Reagents and conditions: (a) NaOMe, MeOH; (b) p-anisaldehyde, PPTS, DMF; (c) TBSCl, imidazole, DMF, 45\% three steps; (d) DIBAL, toluene; (e) $\mathrm{Ph}_{3} \mathrm{P} \cdot \mathrm{HBr}, \mathrm{NaBr}$, MeOH/DME; (f) $\mathrm{I}_{2}$, imidazole; $\mathrm{Ph}_{3} \mathrm{P}$, THF, 69\% three steps; (g) $t$-BuOK, THF, $87 \%$; (h) Hg(OCOCF $)_{2}(20$ mol\%), acetone/acetate buffer; (i) $\mathrm{MsCl}, \mathrm{Et}_{3} \mathrm{~N}, \mathrm{DMAP}, \mathrm{CH}_{2} \mathrm{Cl}_{2}, 91 \%$ two steps; (j) $\mathrm{L}$-Selectride, THF, $-78{ }^{\circ} \mathrm{C}$, then 188, 89\%; (k) $190, \mathrm{Pd}(\mathrm{OAc})_{2}, \mathrm{Ph}_{3} \mathrm{P}$, aq. $\mathrm{Na}_{2} \mathrm{CO}_{3} / \mathrm{dioxane}$, quant.; (I) DDQ, aq. $\mathrm{CH}_{2} \mathrm{Cl}_{2}, 83 \%$; (m) TBAF, THF, quant; (n) 2-nitrophenol, $\mathrm{CH}_{3} \mathrm{C}(\mathrm{OEt})_{3}, 140{ }^{\circ} \mathrm{C}$, in a sealed tube; (o) $m$ - $\mathrm{CPBA} \mathrm{CH}_{2} \mathrm{Cl} \mathrm{C}_{2}$; (p) TBSCl, imidazole, DMF, $73 \%$; (q) DIBAL-H (2 equiv.), toluene, $-78^{\circ} \mathrm{C}$; (r) Montmorillonite $\mathrm{K}-10,\left(\mathrm{CH}_{2} \mathrm{Cl}_{2}\right)_{2}$, r.t.; (s) TBSOTf, 2,6-lutidine, $\mathrm{CH}_{2} \mathrm{Cl}_{2}, 75 \%$ three steps; (t) $\mathrm{MeNH}_{2}, \mathrm{MeNH}_{3} \mathrm{Cl}, \mathrm{MS}_{3} \mathrm{~A}$, THF, then $\mathrm{LiBH}_{4}$; (u) TBSCl, DMAP, pyridine; (v) TBAF, THF, 86\% three steps; (w) Li, $t$ - $\mathrm{BuOH}$, liq. $\mathrm{NH}$, THF, $92 \%$.

图式 21 Chida 研究组的合成方法

Scheme 21 Synthesis by Chida's group<smiles>COc1cccc(I)c1OC(=O)CC1=CCC2(CC1)OCCO2</smiles><smiles>COc1cccc2c1O[C@H]1C[C@@H](O)C=C[C@@]21CCN(C)C</smiles>

205<smiles>COc1cccc2c1OC(=O)CC21C=CC2(CC1)OCCO2</smiles>

202<smiles>COc1cccc2c1OC(=O)CC21C=CC(=O)C=C1</smiles>

203<smiles>COc1cccc2c1O[C@H]1CC(=O)C=CC21CC(=O)NCc1ccccc1</smiles>

204

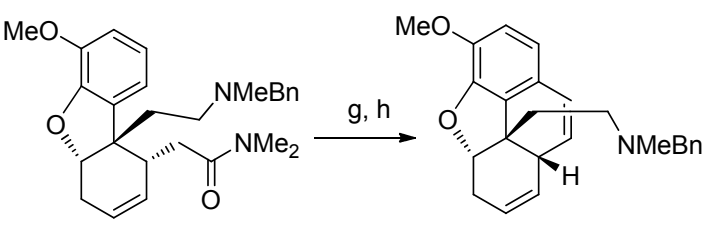

207

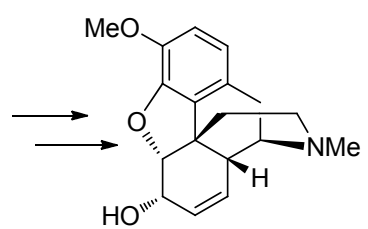

2 Codeine

Reagents and conditions: (a) $\mathrm{Pd}_{2}\left(\mathrm{dba}_{3}, \mathrm{NEt}_{3}, \mathrm{DMF}, 140{ }^{\circ} \mathrm{C}, 67 \%\right.$; (b) $\mathrm{Ph}_{3} \mathrm{CBF}_{4}, \mathrm{CH}_{2} \mathrm{Cl}_{2}$; (c) $(\mathrm{PhSeO})_{2} \mathrm{O}, \mathrm{NaHCO}_{3}, \mathrm{PhCl}, 60 \%$; (d) $\mathrm{NHMeBn}$, THF; (e) $\mathrm{LiAlH}_{4}$, THF, $77 \%$ two steps; (f) decaline, $215^{\circ} \mathrm{C}, 49 \%$; (g) $\mathrm{Ti}(\mathrm{OiPr})_{4}, \mathrm{PhSiH}_{3}$; (h) $p$-TSA, toluene, $40 \%$.

图式 22 Guillou 研究组的合成方法

Scheme 22 Synthesis by Guillou's group 


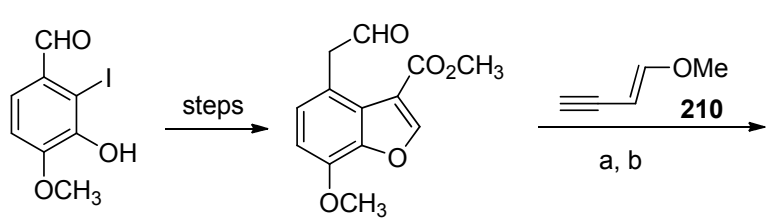

208

209<smiles>C=CC=CC(Cc1ccc(OC)c2c(OC)ccc(C(C)=O)c12)O[C+](C)(F)F</smiles>

211

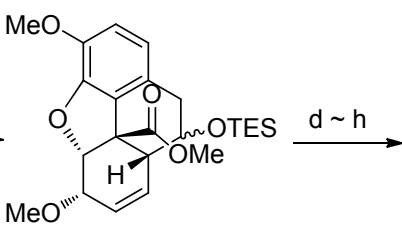

212 $\alpha$-OTES: $\beta$-OTES $=1: 4$<smiles>COC(=O)C12c3ccc(OC)c(c31)O[C@@H]1C(=O)C=CC2C=CC1OC</smiles>

213

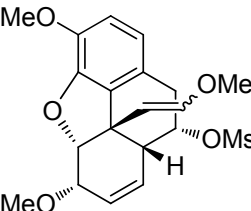

214

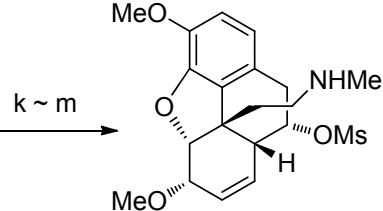

215
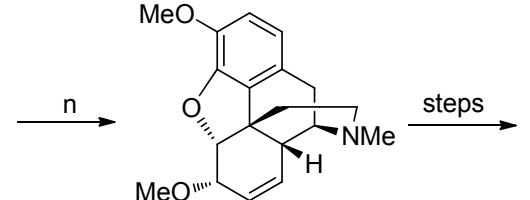<smiles>COC1=CC=C2CCC(C)[C@H]1Oc1c(OC)ccc3c1C23CN</smiles>

3 Thebaine

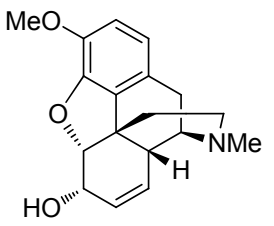

2 codeine

Reagents and conditions: (a) 210, $\mathrm{ZrCp}_{2}(\mathrm{H}) \mathrm{Cl}, \mathrm{AgOTf}, \mathrm{CH}_{2} \mathrm{Cl}_{2}$; (b) TESCl, imidazole, 95\%; (c) Decalin, $\mathrm{Et}_{3} \mathrm{~N}, 240{ }^{\circ} \mathrm{C}$, 69\%; (d) super-hydride, THF; (e) Dess-Martin, $\mathrm{CH}_{2} \mathrm{Cl}_{2}$; (f) $\mathrm{Ph}_{3} \mathrm{PCH}_{2} \mathrm{OCH}_{3} \mathrm{Cl}$, KHMDS, $\mathrm{CH}_{2} \mathrm{Cl}_{2}$ /THF; (g) TBAF, THF; (h) Dess-Martin, $\mathrm{CH}_{2} \mathrm{Cl}_{2}, 51 \%$ five steps; (i) L-Selectride, THF; (j) $\mathrm{MsCl}, \mathrm{Et}_{3} \mathrm{~N}, \mathrm{CH}_{2} \mathrm{Cl}_{2}, 34 \%$ two steps; (k) aq. $\mathrm{HCl}$, THF; (I) $\mathrm{MeNH}_{2} \cdot \mathrm{HCl}, \mathrm{Et}_{3} \mathrm{~N}, \mathrm{Ti}(\mathrm{O} \text { - }-\mathrm{Pr})_{4}, \mathrm{MeOH}$; (m) $\mathrm{NaBH}_{4}, 80 \%$ three steps; (n) $\mathrm{K}_{2} \mathrm{CO}_{3}$, benzene, $73 \%$.

图式 23 Stork 研究组的合成方法

Scheme 23 Synthesis by Stork's group<smiles>CCCCOc1ccc(B2OB(c3ccc(OC(C)(C)C)cc3)OB(c3ccc(O[Sb](C)(=O)=O)cc3)O2)cc1</smiles><smiles>C=COCC</smiles><smiles>CCOc1ccc(-c2c(C=O)ccc(OC)c2OC(CBr)CBr)cc1</smiles>

218<smiles>CC=CC(=O)C=CC1(c2c(C=O)ccc(OC)c2OCC)C=CC(=O)C=C1</smiles>

221<smiles>[Li][Mg][Mg]</smiles><smiles></smiles>

222<smiles>CC(C)C</smiles><smiles>CCOC1C=CC2(CCC(=O)C2)[C@H]([N+](=O)[O-])Cc2ccc(OC)c1c2</smiles>

223<smiles>CCOCC1(CC(C)(C)C)C=C[C@@H](O)C[C@H]1C(N)CO</smiles>

224

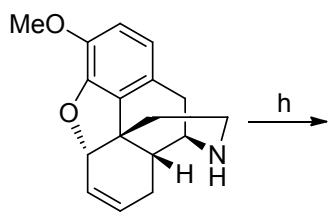

225

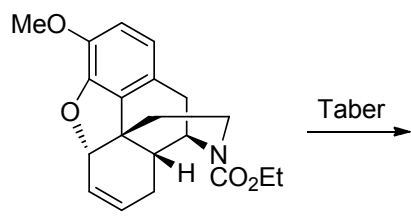

226

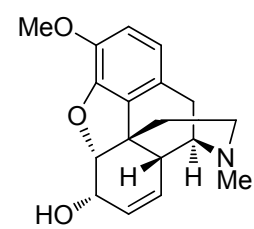

2 codeine

Reagents and conditions: (a) $\mathrm{Pd}_{2}(\mathrm{dba})_{3}, \mathrm{PCy}, \mathrm{BHT}, \mathrm{K}_{2} \mathrm{CO}_{3}$, aq. dioxane, $80{ }^{\circ} \mathrm{C}, 99 \%$; (b) Ethyl vinyl ether, $\mathrm{Br}_{2}, i-\mathrm{Pr}_{2} \mathrm{NEt}_{3} \mathrm{CH}_{2} \mathrm{Cl}_{2}, 99 \%$; (c) $\mathrm{CsF}$, DMF, $130{ }^{\circ} \mathrm{C}, 96 \%$; (d) $\mathrm{MeNO}_{2}, \mathrm{NH}_{4} \mathrm{OAc}, \mathrm{AcOH}$, reflux, 97\%; (e) $\mathrm{NaCNBH}_{3}, \mathrm{AcOH}, \mathrm{THF}, 88 \%$; (f) $\mathrm{LiAlH}_{4}, \mathrm{THF}, 72 \%$; (g) $1 \mathrm{~mol} / \mathrm{L} \mathrm{HCl}$ $\mathrm{NaCNBH}_{3}$, dioxane, $66 \%$; (h) $\mathrm{ClCO}_{2} \mathrm{Et}, \mathrm{Et}_{3} \mathrm{~N}, \mathrm{CH}_{2} \mathrm{Cl}_{2}, 90 \%$.

图式 24 Magnus 研究组的合成方法

Scheme 24 Synthesis by Magnus's group 
$L$-selectride 还原成羟基, 羟基由 TBS 保护得到化合物 232, 化合物 232 经三氯化硼诱导的烯丙基重排, 随后溶 剂二氯甲烷中的氯代反应和羟基取代反应得到化合物 233, 化合物 233 通过 Eschenmoser-Claisen 重排反应构 建了含芳环的手性季碳得到化合物 234, 化合物 234 经 还原成伯醇, 随后 Ts 保护成化合物 235. 化合物 235 在 Raney 镍的作用下自发地发生了分子内的烷基化反应得 到桥环化合物 236. 化合物 236 在脱除 TBS 后, 三溴化 硼的作用下醚键断裂，新生的酚羟基进攻烯丙位构筑了 二氢呋喃环，随后再甲基化得到化合物 237. 化合物 237 最后经烯丙基迁移和 DMP 氧化得到可待因酮, 可待因 酮通过硼氢化钠还原羰基得到目标分子可待因(Scheme 25).

\subsection{5 樊春安研究组的合成方法}

2013 年樊春安课题组 ${ }^{[47]}$ 设计了串联醇解/氧杂 Michael 加成反应和 $\mathrm{SmI}_{2}$ 促进的自由基还原偶联/去硫 化反应为关键步骤的合成路线合成了 Hudlicky 路线的
前体，完成了吗啡的形式全合成. 该路线合成化合物 239 后经醋酸碘苯的氧化偶联得到化合物 240 , 化合物 240 在氯铬酸吡啶(PCC)的氧化作用后得到内酯化合物 241, 内酯化合物 241 经一步串联醇解/氧杂 Michael加成 反应成功构建了吗啡的三环骨架, 随后经一步非立体选 择性的还原后得到化合物 242, 化合物 242 经历苯硫酚 的亲核取代反应后得到硫醚化合物 243 , 硫醚化合物 243 经酯基的还原氧化得到化合物 244, 化合物 244 经还 原胺化再上 Boc 保护基之后脱除 TBS 保护, DMP 氧化 成醛得到化合物 245, 化合物 245 在经关键步骤 $\mathrm{SmI}_{2}$ 促 进的自由基还原偶联/去硫化反应后成功构建了吗啡的 四环骨架 246. 化合物 246 在之后的官能团转化和修饰 后得到 Hudlicky 路线的前体化合物, 完成了吗啡的形式 全合成(Scheme 26).

\subsection{Fukuyama 研究组的合成方法}

2014 年 Fukuyama 课题小组 ${ }^{[48]}$ 以钯催化分子内溴苯 的芳基偶联反应和分子内迈克尔加成反应作为关键步<smiles>COB(C)Oc1cc(C=O)ccc1OC</smiles>

227

228

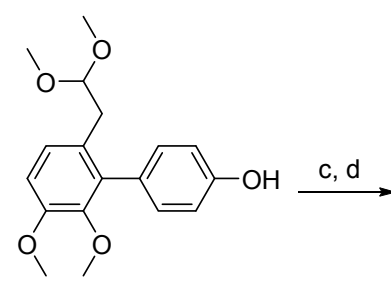

230

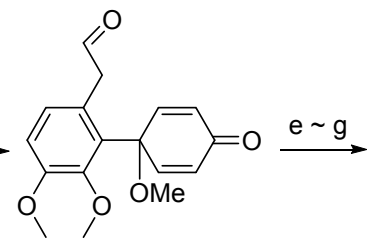

231

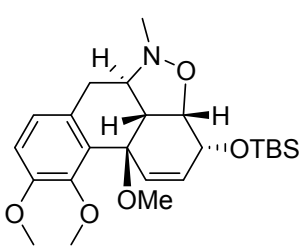

232

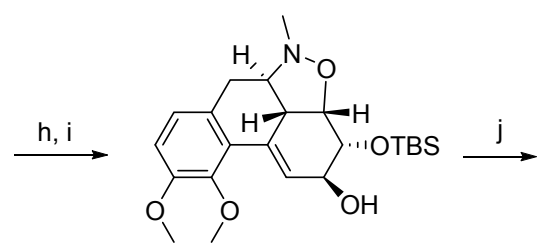

233

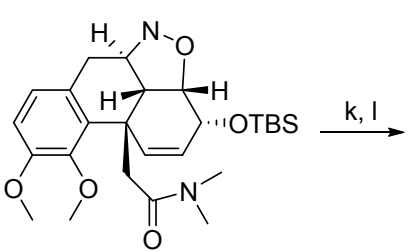

234

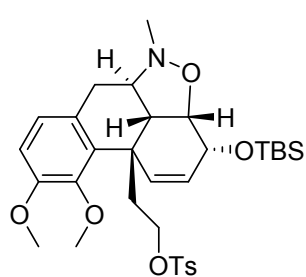

235

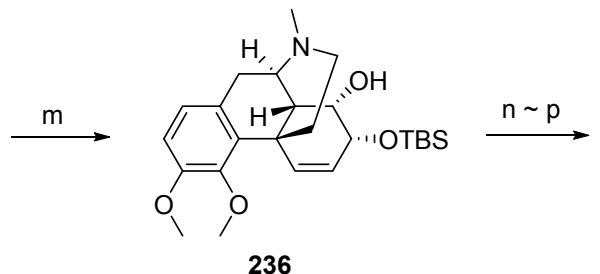

236

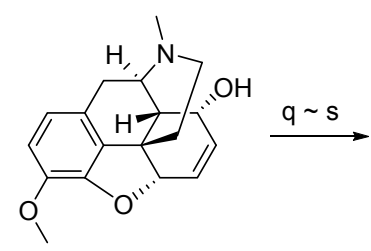

237

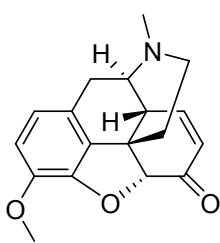

4 codeinone

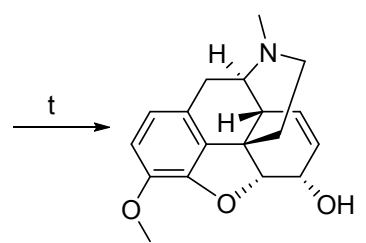

2 codeine

Reagents and conditions: (a) 229, $\mathrm{K}_{2} \mathrm{CO}_{3}, 1,4-d i o x a n e / \mathrm{H}_{2} \mathrm{O}, \mathrm{BHT}, \mathrm{Pd}_{2}\left(\mathrm{dba}_{3}, \mathrm{PCy}_{3}, 80^{\circ} \mathrm{C}\right.$; (b) aq. $\mathrm{NaOH}, 50{ }^{\circ} \mathrm{C}, 95 \%$; (c) $\mathrm{PIDA}, \mathrm{MeOH}, \mathrm{HC}(\mathrm{OMe})_{3}$, r.t., $66 \%$; (d) CAN, MeCN/borate buffer, pH $5 \sim 6,60^{\circ} \mathrm{C}, 97 \%$; (e) $\mathrm{MeNHOH} \bullet \mathrm{HCl}, \mathrm{NaHCO}_{3}, \mathrm{NaSO}_{4}, \mathrm{MeCN}^{\circ}{ }^{\circ} \mathrm{C}$; (f) L-selectride, THF; MeOH; aq. $\mathrm{NaOH}, \mathrm{H}_{2} \mathrm{O}_{2}$, r.t.; (g) TBSCl, imidazole, cat. DMAP, $\mathrm{CH}_{2} \mathrm{Cl}_{2}$, r.t., 80 \% three steps; (h) $\mathrm{BCl}_{3}$, DCM, $-78{ }^{\circ} \mathrm{C}$; $\mathrm{EtN}_{3}$, $\mathrm{MeOH}$, $-78^{\circ} \mathrm{C}$ to r.t.; (i) $\mathrm{ZnO}$, acetone/ $\mathrm{H}_{2} \mathrm{O}, 80^{\circ} \mathrm{C}, 76 \%$; (j) MeC(OMe) ${ }_{2} \mathrm{NMe}_{2}$, toluene, reflux, Dean-Stark trap, 87\%; (k) LDA, $\mathrm{BH}_{3} \cdot \mathrm{NH}_{3}, 0{ }^{\circ} \mathrm{C}$ to r.t., $97 \%$; (I) $p$-TsCl, Et $\mathrm{T}_{3} \mathrm{~N}, \mathrm{DMAP}$, DCM, $0{ }^{\circ} \mathrm{C}$ to r.t.; (m) EtOH/EtOAc, EtN ${ }_{3}$, Raney Ni, $101 \mathrm{kPa} \mathrm{H}$, r.t., $86 \%$; (n) TBAF, THF, $0{ }^{\circ} \mathrm{C}, 100{ }^{\circ} \mathrm{C}$; (o) $\mathrm{BBr}_{3}$, DCM, $-65^{\circ} \mathrm{C}$; aq. $\mathrm{NaHCO}_{3}$, r.t.; (p) $\mathrm{Me}_{3} \mathrm{NPhCl}, \mathrm{NaOEt}$, toluene, reflux, $80 \%$; (q) $\mathrm{SOCl}_{2}, 0^{\circ} \mathrm{C}$ to r.t., $77 \%$; (r) 1,4-dioxane/ $\mathrm{H}_{2} \mathrm{O}, 100 \%$, microwave irradiation, $72 \%$; (s) $\mathrm{DMP}, \mathrm{NaHCO}$, DCM, r.t., $29 \%$; (t) $\mathrm{NaBH}_{4}, \mathrm{MeOH}$, r.t., $99 \%$.

图式 25 Metz 研究组的合成方法

Scheme 25 Synthesis by Metz's group 
<smiles>COc1ccc(CCO[R15](=O)c2ccc(OC)c(O)c2)cc1</smiles>

238<smiles>COc1ccc(CCOS(=O)(=O)Oc2ccc(O)cc2)cc1OC(CO)CO</smiles>

239<smiles>COc1ccc(CCOC(C)C)c2c1OC(CO)CC21C=CC(=O)C=C1</smiles>

240<smiles>COc1ccc(CCOC(C)C)c2c1OC(=O)CC21C=CC(=O)C=C1</smiles>

241

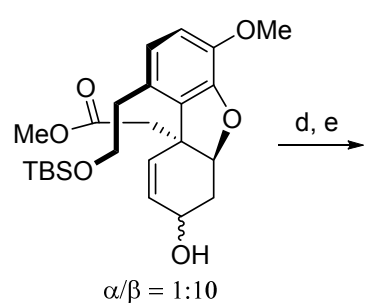

242

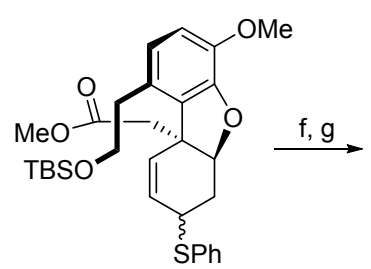

( \pm )-243- $\alpha /( \pm)-243-\beta$ separable $(\alpha . \beta=10: 1)$<smiles></smiles>

244<smiles>COc1ccc(CCN(C)C(=O)OC(C)(C)C)c2c1OC1CC([SnH+])C=CC21CC=O</smiles>

S̄Ph

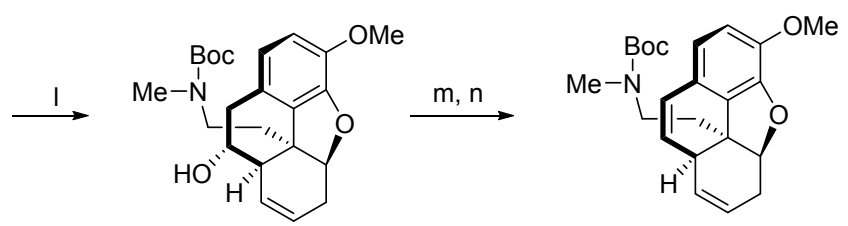

246

Hudlicky intermadiate

Reagents and conditions: (a) Phl $(\mathrm{OAc})_{2},\left(\mathrm{CF}_{3}\right)_{2} \mathrm{CHOH}, \mathrm{NaHCO}_{3}, 85 \%$; (b) PCC, $3 \AA \mathrm{AS}$, benzene, reflux, $38 \%$; (c) $\mathrm{MeOH}, \mathrm{NaN}_{3}$, then $\mathrm{NaBH} 4,0$ ${ }^{\circ} \mathrm{C}, 82 \%$; (d) $\mathrm{MsCl}, \mathrm{NEt}_{3}, \mathrm{CH}_{2} \mathrm{Cl}_{2},-78$ to $0{ }^{\circ} \mathrm{C}$; (e) $\mathrm{PhSH}, \mathrm{Cs}_{2} \mathrm{CO}_{3}, n-\mathrm{Bu}_{4} \mathrm{NI}$, DMF, $0{ }^{\circ} \mathrm{C}$ to r.t., $91 \%$ two steps; (f) DIBAL-H, $\mathrm{CH}_{2} \mathrm{Cl}_{2},-78$ to $0{ }^{\circ} \mathrm{C}$; (g) Dess-Matin periodinane, $\mathrm{CH}_{2} \mathrm{Cl}_{2}, 0{ }^{\circ} \mathrm{C}$ to r.t., $84 \%$ two steps; (h) $\mathrm{MeNH}_{2}, \mathrm{MeOH}$, then $\mathrm{NaBH}_{4}$; (i) (BOC) ${ }_{2} \mathrm{O}, \mathrm{NEt}_{3}, \mathrm{DMF}$, $76 \%$ two steps; (j) $n$ $\mathrm{Bu}_{4} \mathrm{NF}$, THF; (k) DMP, $\mathrm{CH}_{2} \mathrm{Cl}_{2}, 76 \%$ two steps; (I) $\mathrm{Sml}_{2}$, HMPA, THF, $-40{ }^{\circ} \mathrm{C}$ to r.t., $68 \%$; (m) MsCl, $\mathrm{NEt}_{3}, \mathrm{CH}_{2} \mathrm{Cl}_{2}, 0^{\circ} \mathrm{C}$; (n) DBU, PhMe, reflux, $94 \%$ two steps.

图式 26 禁春安研究组的合成方法

Scheme 26 Synthesis by Fan's group

骤合成了一个半合成类鸦片镇痛剂(一)-Oxycodone. 该 合成路线利用化合物 247 和 248 在强碱的作用下制备化 合物 249. 化合物 249 移去手性辅基后甲氧基化以高收 率得到化合物 $\mathbf{2 5 0}$. 化合物 $\mathbf{2 5 0}$ 经一步钯催化分子内溴 苯的芳基偶联反应得到化合物 $\mathbf{2 5 1}$ 和少量二溴代的产物 252. 化合物 251 经还原、醋酸酯保护、脱出苄基得到化 合物 253. 化合物 253 在醋酸碘苯氧化去芳化的作用下 得到化合物 254. 化合物 254 经氢化反应和单酯单酰氯 保护得到化合物 256. 化合物 256 在碳酸铯的作用下进 行了分子内的迈克尔加成反应得到化合物 257. 化合物 $\mathbf{2 5 7}$ 脱酯和脱 MOM 保护基得到化合物 258. 化合物 258 在羰基 $\alpha$ 位溴代后在碱性条件下环合构筑吗啡的二氢呋 喃环结构得到化合物 259. 化合物 259 经脱保护缩合过 程得到酰胺化合物 260 . 酰胺化合物 260 经水解过程自 发生成内酰胺化合物 261. 内酰胺化合物 261 经还原氧 化等过程最终获得半合成类鸦片镇痛剂(-)-Oxycodone (Scheme 27).

\subsection{Gaunt 研究组的合成方法}

2014 年, Gaunt 研究小组 ${ }^{[49}$ 报道了以邻对位苯酚的 氧化自由基偶联为策略立体专一性高效合成吗啡类生 物碱衍生物的方法. 该方法以化合物 268 作为进行邻对 位苯酚的氧化自由基偶联反应的前体，在醋酸碘苯的作 用下将化合物 268 氧化偶联生成一个中间体, 这个中间 体并未进行纯化, 在 DBU 的作用下, 实现了去对称化 的区域选择性 Michael 加成反应, 以一锅法 48\%的收率 得到化合物 269. 随后化合物 269 经 Picnic 氧化成酸, Curtius 重排得到 Boc-保护的胺化合物 270. 之后脱除硅 保护基, DBU 作用下甲磺酸酯脱双键得到烯醇醚化合物 271. 化合物 271 经 Luche 还原成醇, 在微波的酸性条件 下烯醇醚键水解, 酚差基进攻烯丙位的正离子构筑了二 氢呋喃环, 与此同时 Boc-脱除的胺与醛形成亚胺, 亚胺 还原胺化再经保护得到吗啡类生物碱衍生物 272. 本路 线立体选择性地以 $4.3 \%$ 的收率历经 18 步得到吗啡类生 物碱衍生物 272 完成了吗啡的形式全合成(Scheme 28). 
<smiles>COc1ccc(CBr)c(Br)c1OC</smiles>

247<smiles>COC(=O)C(Cc1ccc(OC)c(OC)c1OC)c1ccc(OCc2ccccc2)cc1</smiles><smiles>COC(=O)[C@H]1Cc2ccc(OC)c(OC)c2-c2cc(Cc3ccccc3)ccc21</smiles>

251

debrominated product

252<smiles>COc1ccc2c(c1OC)-c1cc(O)ccc1C(COC(C)=O)C2</smiles>

253<smiles>COc1ccc2c(c1OC)C1=CC(=O)C=CC1(O)C(COC(C)=O)C2</smiles>

254<smiles>COc1ccc2c(c1OC)C1=CC(=O)CCC1(O)C(COC(C)=O)C2</smiles>

255<smiles>COc1ccc2c(c1OC)C1=CC(=O)CCC1(OC(=O)CC(C)=O)C2COC(C)=O</smiles>

256

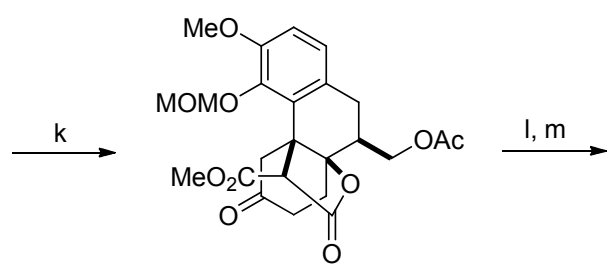

257<smiles>COc1ccc2c(c1O)C1(CC(=O)CC1COC(C)=O)CC(=O)OC21CCCCC1</smiles>

258

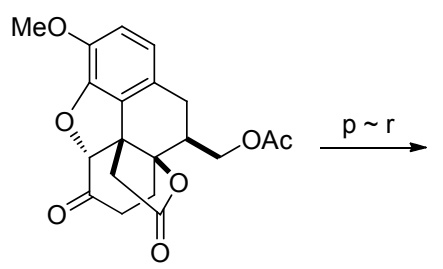

259<smiles>COc1ccc2c3c1O[C@H]1C(=O)CC(C)(C)CC31C(C(N)=O)OC2=O</smiles>

260<smiles>COc1ccc2c3c1O[C@H]1C(=O)CC[C@]3(C(=O)O)[C@]21C(C)=O</smiles>

261

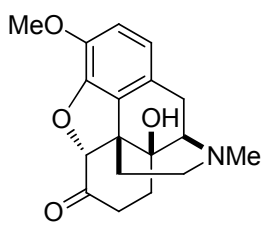

$262(-)-$ - Oxycodone

Reagents and conditions: (a) 248, NaHMDS, THF, -78 to $0{ }^{\circ} \mathrm{C}, 88 \%\left(d r>40: 1\right.$ ); (b) $\mathrm{H}_{2} \mathrm{O}_{2}$ aq., LiOH aq., THF- $\mathrm{H}_{2} \mathrm{O}, 0^{\circ} \mathrm{C}$; (c) $\mathrm{TMSCHN}_{2}$, MeOH$\mathrm{CH}_{2} \mathrm{Cl}_{2}$, r.t., $94 \%$ two steps; (d) $\mathrm{Pd}(\mathrm{OAc})_{2}$ (15 mol\%), $\mathrm{Ph}_{3} \mathrm{P}(45 \mathrm{~mol} \%), \mathrm{K}_{2} \mathrm{CO}_{3}$ (3.0 equiv.), $\mathrm{PivOH}(30 \mathrm{~mol} \%), 1,4-$ dioxane, $100{ }^{\circ} \mathrm{C}, 98 \%, 14: 15=$ 13:1; (e) $\mathrm{LiAlH}_{4}$, THF, $0{ }^{\circ} \mathrm{C}$; (f) $\mathrm{Ac}_{2} \mathrm{O}$, pyridine, rt.; (g) $\mathrm{H}_{2}$, $\mathrm{Pd} / \mathrm{C}, \mathrm{MeOH}$, r.t., $89 \%$ three steps; (h) PhI(OAc) $)_{2}, \mathrm{HFIP}-\mathrm{H}_{2} \mathrm{O},-20^{\circ} \mathrm{C}, 69 \%$; (i) $\mathrm{H}_{2}(200$ psi), $\mathrm{RhCl}\left(\mathrm{PPh}_{3}\right)_{3}$, benzene, $50{ }^{\circ} \mathrm{C}, 86 \%$; (j) Methyl 4-chloroacetoacetate, pyridine, $\mathrm{CH}_{2} \mathrm{Cl}_{2}, 0{ }^{\circ} \mathrm{C}$ to r.t.; $(\mathrm{k}) \mathrm{Cs}_{2} \mathrm{CO}_{3}, \mathrm{MeCN}^{\circ} 60{ }^{\circ} \mathrm{C}$; (l) $\mathrm{NaCl}, \mathrm{H}_{2} \mathrm{O}$, DMSO, $120{ }^{\circ} \mathrm{C}$; (m) TFA, $\mathrm{CH}_{2} \mathrm{Cl}_{2}, 0{ }^{\circ} \mathrm{C}, 80 \%$ four steps; (n) $\mathrm{PyHBr}_{3}, \mathrm{CH}_{2} \mathrm{Cl}_{2}-\mathrm{AcOH}$, r.t.; (o) $\mathrm{Et}_{3} \mathrm{~N}$, Lil, $\mathrm{MeCN}, 60{ }^{\circ} \mathrm{C}, 60 \%$ two steps; (p) $\mathrm{K}_{2} \mathrm{CO}_{3}$, $\mathrm{MeOH}$, r.t., $71 \%$; (q) $\mathrm{CrO}_{3}, \mathrm{H}_{2} \mathrm{SO}_{4}$, acetone- $\mathrm{H}_{2} \mathrm{O}, 0{ }^{\circ} \mathrm{C}$ to r.t.; (r) DMTMM, $\mathrm{NH}_{3}$ aq, $\mathrm{MeOH}$, r.t., $49 \%$ two steps; (s) $\mathrm{Phl}(\mathrm{OAc})_{2}, \mathrm{MeCN}-\mathrm{H}_{2} \mathrm{O}, 40{ }^{\circ} \mathrm{C}$, $78 \%$; (t) $\mathrm{BH}_{3} \bullet \mathrm{THF}$, THF, reflux; $\mathrm{MeOH}$, r.t.; $\mathrm{AcOH}, \mathrm{HCHO}$ aq. $\mathrm{NaBH}(\mathrm{OAc})_{3}$; (u) DMP, $\mathrm{CH}_{2} \mathrm{Cl}_{2}$, r.t., $46 \%$ two steps.

图式 27 Fukuyama 研究组的合成方法

Scheme 27 Synthesis by Fukuyama's group

\subsection{Hudlicky 研究组的合成方法}

2014 年, Hudlicky 课题小组 ${ }^{[50]}$ 报道了以氧化去芳化 和分子内 $\mathrm{DA}$ 反应为关键步骤合成对映二氢吗啡酮 (ent-Hydromorphone) 的简短合成路线. 路线首先利用 Mitsunobu 反应将化合物 273 和化合物 274 偶联形成化 合物 275, 化合物 $\mathbf{2 7 5}$ 中的醛基进行一步 Wittig 反应转 化为烯基官能团生成化合物 276, 化合物 276 在温和的 条件下移除 MOM 保护基得到化合物 277, 化合物 277 通过关键步骤氧化去芳化和 DA 反应经去芳化的中间体
278 转化为化合物 279 , 这样就成功构建了吗啡骨架中 的 B 环. 化合物 279 在三氟乙酸的作用下再次芳构化得 到中间体化合物 $\mathbf{2 8 0}$, 化合物 $\mathbf{2 8 0}$ 经 Ts 保护和 TBS 保护 基脱出后得到胺化的前体化合物 281, 化合物 281 经 Birch 还原条件下胺化构筑 D 环得到化合物 282, 化合物 282 最后通过一步苯甲酮和叔丁醇钾的氧化得到对映二 氢吗啡酤(ent-Hydromorphone)，该合成路线用简短的 12 步就高效地合成了对映二氢吗啡酮 (ent-Hydromorphone) (Scheme 29). 


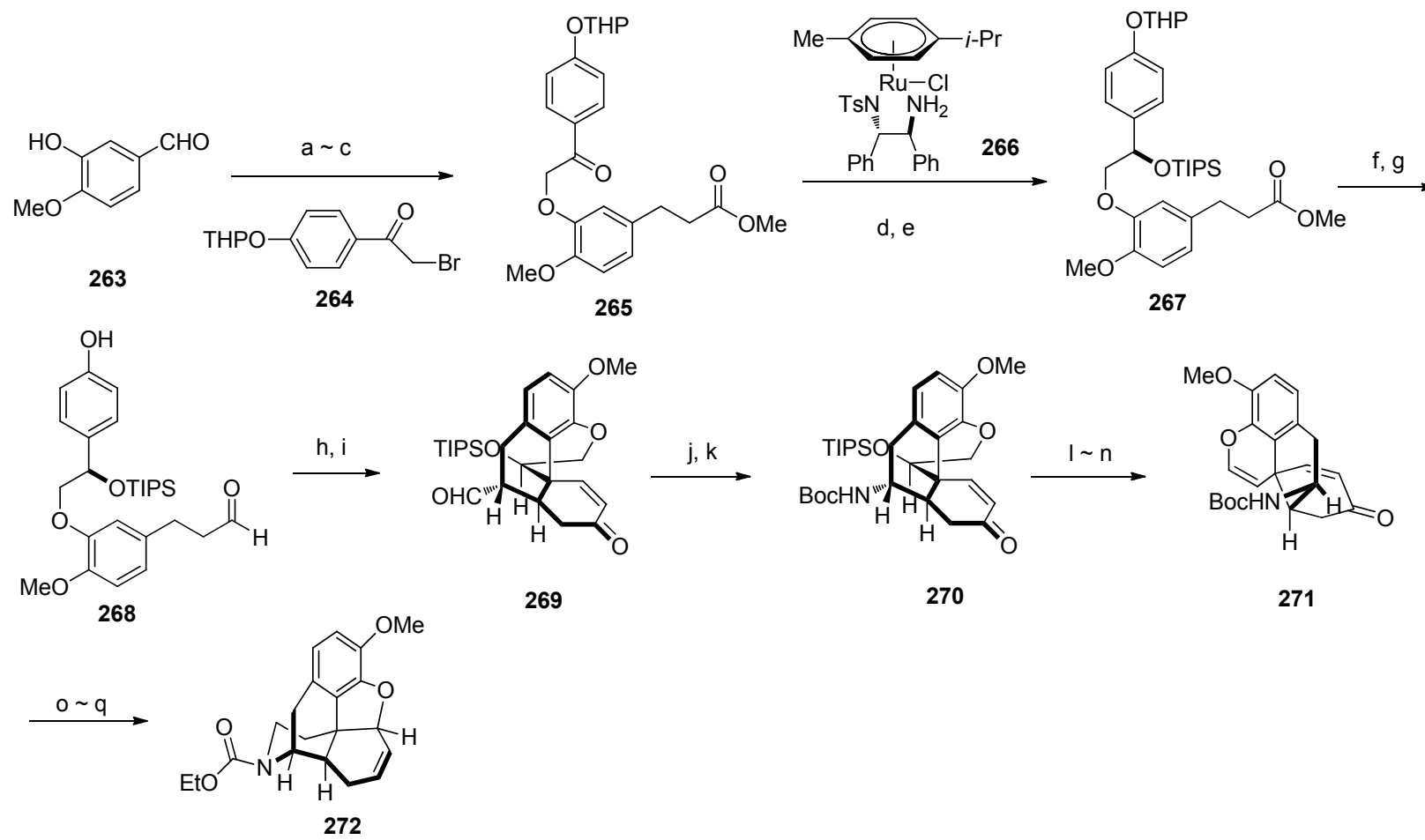

Reagents and conditions: (a) $\mathrm{Ph}_{3} \mathrm{PCHCO}_{2} \mathrm{Me}, \mathrm{Ch}_{2} \mathrm{Cl}_{2}$, reflux; (b) $\mathrm{H}_{2}$, $\mathrm{Pd} / \mathrm{C}$, MeOH, r.t., DIBAL, $\mathrm{CH}_{2} \mathrm{Cl}_{2},-78{ }^{\circ} \mathrm{C}$; (c) 264, $\mathrm{K}_{2} \mathrm{CO}_{3}, n-\mathrm{Bu}_{4} \mathrm{NBr}$, $\mathrm{CH}_{2} \mathrm{Cl}_{2} / \mathrm{H}_{2} \mathrm{O}, 55{ }^{\circ} \mathrm{C}, 89 \%$ three steps; (d) 266, $\mathrm{HCO}_{2} \mathrm{H} / \mathrm{Et}_{3} \mathrm{~N} / \mathrm{DMF}, 40{ }^{\circ} \mathrm{C}$; (e) TIPSOTf, $i \mathrm{Pr}_{2} \mathrm{NEt}, \mathrm{CH}_{2} \mathrm{Cl}_{2}, 0{ }^{\circ} \mathrm{C}$ to r.t., $80 \%$ two steps; (f) DIBAL, $\mathrm{CH}_{2} \mathrm{Cl}_{2},-78{ }^{\circ} \mathrm{C}$; (g) $3 \mathrm{M} \mathrm{HCl}$, THF, r.t., $94 \%$ two steps; (h) Phl(OAc) , TFE, $-40{ }^{\circ} \mathrm{C}$; (i) DBU, $\mathrm{CH}_{2} \mathrm{Cl}_{2}$, r.t., $48 \%$ two steps; (j) $\mathrm{NaClO}_{2}, \mathrm{NaH}_{2} \mathrm{PO}_{4}, t-$ $\mathrm{BuOH} / \mathrm{H}_{2} \mathrm{O}$, 2-Methyl-2-butene, $0{ }^{\circ} \mathrm{C}$ to r.t.; (k) DPPA, NEt ${ }_{3}, t \mathrm{BuOH}, 65$ to $85{ }^{\circ} \mathrm{C}, 53 \%$ two steps; (I) TBAF, THF, r.t.; (m) MsCl, Et ${ }_{3} \mathrm{~N}, \mathrm{DMAP}^{\circ}$, $\mathrm{CH}_{2} \mathrm{Cl}_{2}, 0^{\circ} \mathrm{C}$; (n) DBU, MeCN, $85^{\circ} \mathrm{C}, 72 \%$ three steps; (o) $\mathrm{NaBH}_{4}, \mathrm{CeCl}_{3} \cdot 7 \mathrm{H}_{2} \mathrm{O}, \mathrm{MeOH},-78{ }^{\circ} \mathrm{C}$; (p) $\mathrm{HCl}$, dioxane, $80^{\circ} \mathrm{C}, \mu \mathrm{W}$; (q) $\mathrm{NaBH}(\mathrm{OAc})_{3}$, $\mathrm{AcOH} / \mathrm{DCE}$, r.t., then $\mathrm{ClCO}_{2} \mathrm{Et}, \mathrm{Et}_{3} \mathrm{~N}$, r.t., $35 \%$ four steps.

图式 28 Gaunt 研究组的合成方法

Scheme 28 Synthesis by Gaunt's group

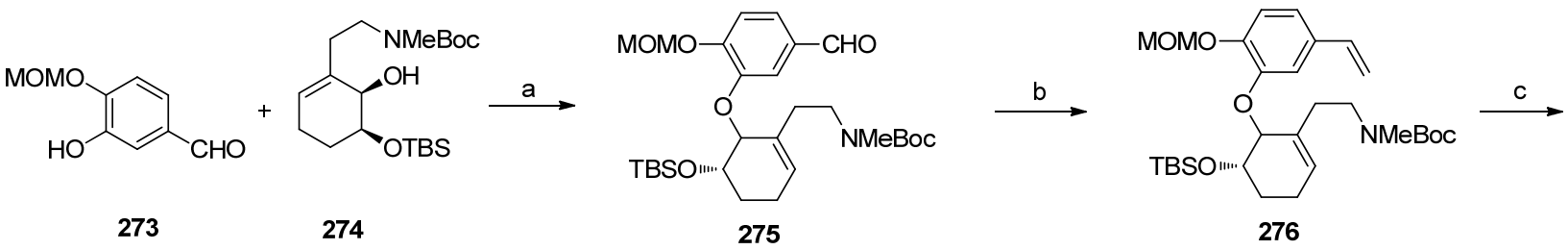

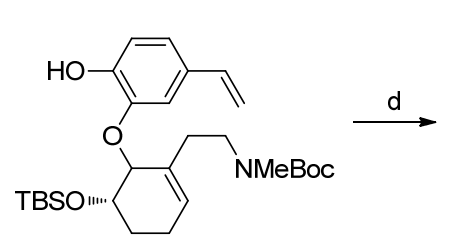

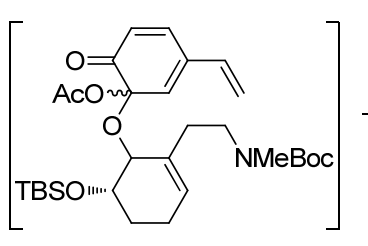

278

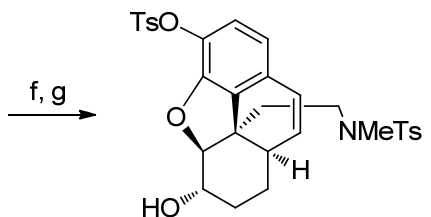

281

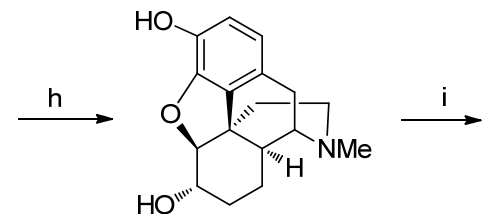

282

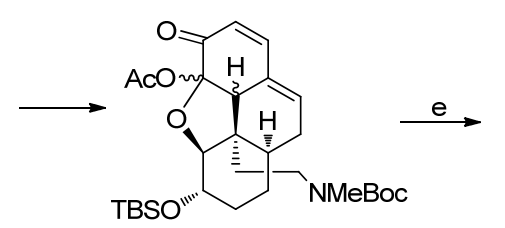

279

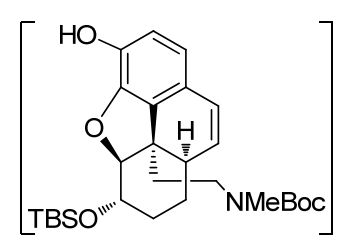

280

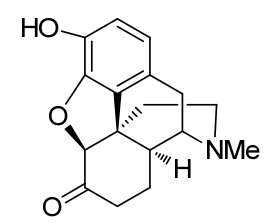

283 ent-hydromorphone

Reagents and conditions: (a) TMAD, $\mathrm{PBu}_{3}, 81 \% \sim 85 \%$; (b) $\mathrm{CH}_{3} \mathrm{PPh}_{3} \mathrm{Br}, n-\mathrm{BuLi}, \mathrm{THF},-78$ to $0{ }^{\circ} \mathrm{C}$, then reflux, $82 \% \sim 88 \%$; (c) $\mathrm{ZnBr}$ $\mathrm{CH}_{3}\left(\mathrm{CH}_{2}\right)_{10} \mathrm{CH}_{2} \mathrm{SH}, \mathrm{CH}_{2} \mathrm{Cl}_{2}$, r.t., $92 \%$; (d) $\mathrm{Pb}(\mathrm{OAc})_{4}, \mathrm{DCE}$, reflux, $50 \%$; (e) TFA, $\mathrm{CH}_{2} \mathrm{Cl}_{2}, 0{ }^{\circ} \mathrm{C}$; (f) $\mathrm{TsCl}^{\circ} \mathrm{Et}_{3} \mathrm{~N}, \mathrm{CH}_{2} \mathrm{Cl}_{2}, 0{ }^{\circ} \mathrm{C}$ to r.t., $45 \%$ two steps; (g) TBAF, THF, r.t., $86 \%$; (h) Li, $t$-BuOH, $\mathrm{NH}_{3}$ (liq), THF, $-78{ }^{\circ} \mathrm{C}, 93 \%$; (i) $t$-BuOK, $\mathrm{PhCOPh}, \mathrm{PhCH}_{3} / \mathrm{DME}^{\circ} 85^{\circ} \mathrm{C}, 44 \%$.

图式 29 Hudlicky 研究组的合成方法

Scheme 29 Synthesis by Hudlicky's group 


\subsection{Opatz 研究组的合成方法}

2014 年, Opatz 课题组 ${ }^{[51]}$ 是基于生源途径的启发来 合成吗啡类生物碱的，路线中利用 Noyori 不对称催化 剂催化氢化反应实现了化合物 286 向化合物 287 的转 化, 之后用 Grewe 环化反应作为合成的关键步骤从化 合物 290 生成化合物 291 成功地构建了吗啡的 $\mathrm{ABCD}$ 四 环骨架, 立体选择性地合成了二氢化可待因 $[(-)$-dihydrocodeine] (Scheme 30).

\subsection{1 张洪彬研究组的合成方法}

2015 年, 本研究组 ${ }^{[52]}$ 从商品化原料苯硼酸的衍生 物出发, 首先一步 Suzuki 偶联反应合成化合物 299, 经 分子内烷基化构建含芳基季碳中心化合物 302, 经选择 性环氧化引入吗啡骨架 C 环官能团合成化合物 $\mathbf{3 0 5}$, 继 而串联环合反应构筑苯并二氢呋喃环得化合物 306, 利 用 Pd 催化的分子内 $\mathrm{C}-\mathrm{H}$ 烯基化反应构建吗啡 B 环, 确 立了吗啡的基本骨架得化合物 307, 之后经一系列官能 团化合成 311(Guillou 中间体), 共 14 步完成了天然产物 可待因( \pm )-Codeine 的全合成(Scheme 31).

\subsection{Smith 研究组的合成方法}

2016 年, Smith 研究组 ${ }^{[33]}$ 报道了一条简短地、立体
选择性地合成吗啡的路线. 该路线从化合物 312 出发, 经苯酚烯基化和钯催化的 $\mathrm{sp}^{3}-\mathrm{sp}^{2}$ 偶联反应得化合物 316, 利用光环化反应立体选择性地构建了吗啡骨架中 的苯并呋喃环化合物 317, 继而通过一系列烯烃-炔烃烯烃的环化反应作为关键步骤高效地合成吗啡的基本 骨架的 BC 两环得到化合物 320, 化合物 320 脱去 Boc 保护基经一步氮杂的 1,6 加成反应构筑吗啡骨架 $\mathrm{D}$ 环, 合成天然产物可待因，最后一步去甲基化完成吗啡的消 旋合成，总收率 $6.6 \%$ (Scheme 32).

\section{2 结语与展望}

吗啡及其类生物碱的全合成，长期以来受到了合成 化学家们的关注和重视, 吗啡虽然不是一个庞大的目标 分子, 但它拥有一个高度紧凑的五元环和五个连续的手 性立体化学中心，优秀的生物活性，因而不论从合成的 挑战性及药物化学的角度而言，吗啡及其类似物都是非 常好的合成目标. 为了构建吗啡骨架, 不同的合成路线 及在其合成中发展出的不同合成方法学被运用，在此把 至今合成吗啡类生物碱的有关信息列成表格(Table 1), 其中不乏优秀的代表之作：例如 Fukuyama、Magnus、 Hudlicky 和 Metz 等的工作, 这些工作及其使用的合成<smiles>COc1ccc2c(c1)CCNC2C#N</smiles>

284<smiles>COC(=O)N1CCc2cc(OC)ccc2[C@H]1Cc1cc(OCc2ccccc2)c(OC)c(OCc2ccccc2)c1</smiles>

289<smiles>COc1ccc2c(c1)CCN=C2Cc1cc(O)c(OC)c(OC)c1</smiles>

286

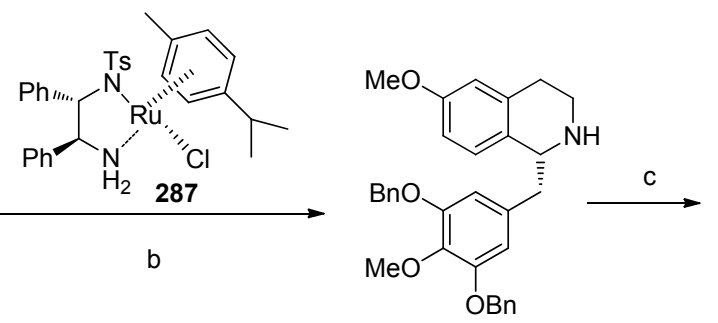

288<smiles>COC(=O)N1CCC2=C(CC=C(OC)C2)[C@H]1Cc1cc(O)c(OC)c(O)c1</smiles>

290

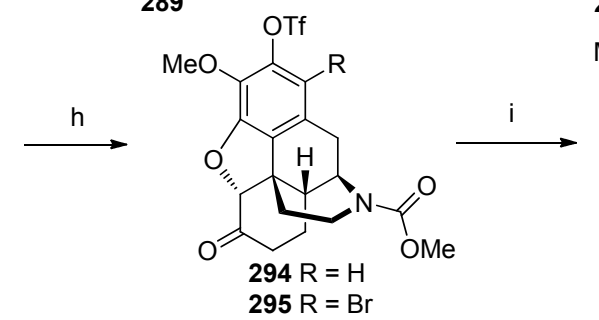

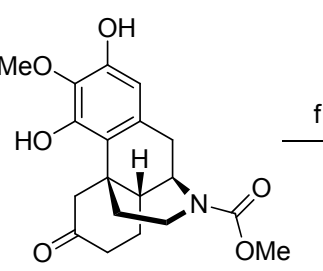

291

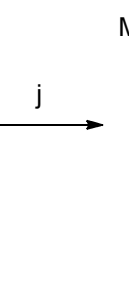

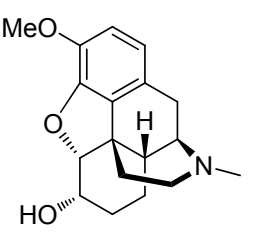

(-)-dihydrocodeine

Reagents and conditions: (a) $\mathrm{KHMDS}$, THF, $-78{ }^{\circ} \mathrm{C}$ to r.t.; (b) 287, $\mathrm{HCO}_{2} \mathrm{H} / \mathrm{NEt}_{3} 5: 2, \mathrm{DMF}, 0{ }^{\circ} \mathrm{C} 68 \%$ two steps, $95 \%$ ee; (c) $\mathrm{ClCO}{ }_{2} \mathrm{Me}$, $\mathrm{THF}$, $\mathrm{NEt}_{3}$, quant; (d) $\mathrm{Li} / \mathrm{NH}_{3}, t$-BuOH, $-78^{\circ} \mathrm{C}$; (e) $\mathrm{HCl} / \mathrm{Et}_{2} \mathrm{O}$, reflux, $88 \%$ two steps; (f) $\mathrm{CuBr}_{2}, \mathrm{CHCl}_{3} / \mathrm{EtOAc}$; (g) $0.5 \mathrm{~mol} / \mathrm{L} \mathrm{NaOH}, 93 \%$ two steps; (h) $\mathrm{Tf}_{2} \mathrm{O}$, pyridine, $0^{\circ} \mathrm{C}, 97 \%$; (i) cat, $\mathrm{Pd}\left(\mathrm{PPh}_{3}\right)_{4}, \mathrm{HCO}_{2} \mathrm{H}, \mathrm{NEt}_{3}, \mathrm{DMF}, 60^{\circ} \mathrm{C}, 80 \%$; (j) DIBAL, THF, $0{ }^{\circ} \mathrm{C}$ to r.t., $81 \%$.

图式 30 Opatz 研究组的合成方法

Scheme 30 Synthesis by Opatz's group 


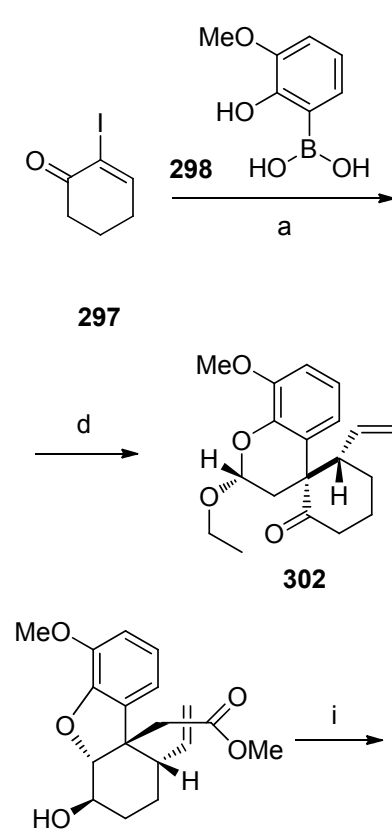

306<smiles>COc1cccc(C2=CCCCC2=O)c1O</smiles>

299<smiles>CCOC(CBr)Oc1c(OC)cccc1C1=CCCCC1=O</smiles>

300<smiles>C=C[C@H]1CCCC(=O)[C@H]1c1cccc(OC)c1OC(CBr)OCC</smiles>

301b: $33 \%$<smiles>C=CC1CCCC(=O)C1c1cccc(OC)c1OC(CBr)(CBr)CBr</smiles>

301a: $59 \%$<smiles>CCCC</smiles><smiles>C=C[C@H]1CCC=C[C@]12C[C@H](OCC)Oc1c(OC)cccc12</smiles>

303<smiles>COC(=O)C1c2ccc(OC)c3c2[C@@]2(CCCC[C@H]2O)[C@H]1O3</smiles>

307

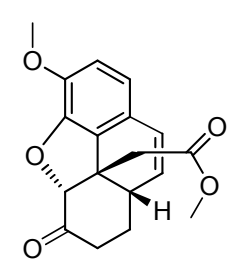

308<smiles>C=C[C@H]1CCC=C[C@]12CC(=O)Oc1c(OC)cccc12</smiles>

304
305

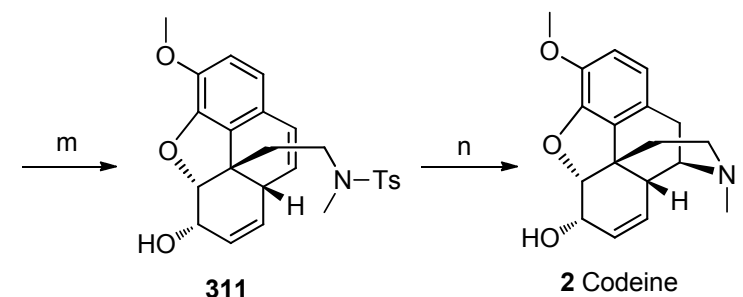

Reagents and conditions: (a) 298, 5\% $\mathrm{Pd}\left(\mathrm{PPh}_{3}\right)_{4}, \mathrm{Na}_{2} \mathrm{CO}_{3}$, dioxane $/ \mathrm{H}_{2} \mathrm{O}, 100{ }^{\circ} \mathrm{C}, 89 \%$; (b) Ethyl vinyl ether, $\mathrm{Br}_{2}, i-\mathrm{Pr}_{2} \mathrm{NEt}, \mathrm{CH}_{2} \mathrm{Cl}{ }_{2}, 0{ }^{\circ} \mathrm{C} \sim$ r.t. 98.6\%; (c) Vinylmagnesium chloride, CuBr•Me $2 \mathrm{~S}, \mathrm{TMSCl}, \mathrm{THF},-78{ }^{\circ} \mathrm{C}, 92 \%, 301 \mathrm{a}: \mathbf{3 0 1 b}=1.8: 1$; (d) $\mathrm{NaH}$ (powder, 95\%), DMF, $0{ }^{\circ} \mathrm{C}, 95.4 \%$; (e) $\mathrm{NaBH}_{4}, \mathrm{MeOH}, 0{ }^{\circ} \mathrm{C}$, then Burgess reagent, benzene, $90{ }^{\circ} \mathrm{C}, 80 \%$; (f) $\mathrm{TsOH}-\mathrm{H}_{2} \mathrm{O}$, acetone/ $\mathrm{H}_{2} \mathrm{O}, 50{ }^{\circ} \mathrm{C}$, then Jones reagent, acetone, r.t., $87 \%$; $(\mathrm{g}$ ) m-CPBA, $\mathrm{NaHCO}_{3}, \mathrm{CH}_{2} \mathrm{Cl}_{2}$, r.t., 81\%; (h) $\mathrm{NaOH}, \mathrm{MeOH} / \mathrm{THF}, 50{ }^{\circ} \mathrm{C}, 99 \%$; (i) $\mathrm{PdCl}_{2}$ (10\%), $\mathrm{CuCl}_{2}$ (2 equiv.), THF, O $\mathrm{O}_{2}$, reflux, $69 \%$; (j) Dess-Martin periodate, $\mathrm{NaHCO}_{3}, \mathrm{CH}_{2} \mathrm{Cl}_{2}, 99 \%$; (k) TMSOTf, $\mathrm{Et}_{3} \mathrm{~N}, \mathrm{CH}_{2} \mathrm{Cl}_{2} ; \mathrm{Pd}(\mathrm{OAC})_{2}, \mathrm{MeCN}, 60 \%$; (I) DIBAL-H, $\mathrm{CH}_{2} \mathrm{Cl}_{2},-78{ }^{\circ} \mathrm{C}, 73 \%$; (m) $\mathrm{MeNH}, \mathrm{MeOH}$, $\mathrm{NaBH}_{4} ; p$-TsCl, DMAP, Pyridine, $80 \%$; (n) $\mathrm{Li}, \mathrm{NH}_{3}(\mathrm{I}), t-\mathrm{BuOH}, \mathrm{THF},-78{ }^{\circ} \mathrm{C}, 60 \%$.

图式 31 张洪涁研究组的合成方法

Scheme 31 Synthesis by Zhang's group<smiles>C=CCc1ccc(OC)c(O)c1</smiles>

312<smiles>C=CCc1cc(OC)c(OC2=C(Br)COC2=O)c(OCC)c1</smiles>

313<smiles>C=CCc1ccc(OC)c(OC2=C(CCN(C)C(=O)OC(C)(C)C)COC2=O)c1</smiles>

316<smiles>C=CCc1cc(C)c(OC)c2c1C(CCN(C)C(=O)OC(C)(C)C)(C(=O)OC)C(COC)O2</smiles>

317

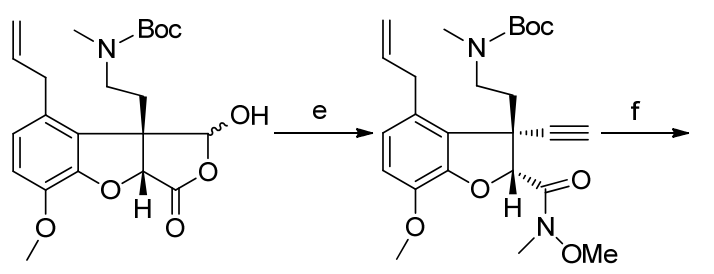

318<smiles></smiles>

320

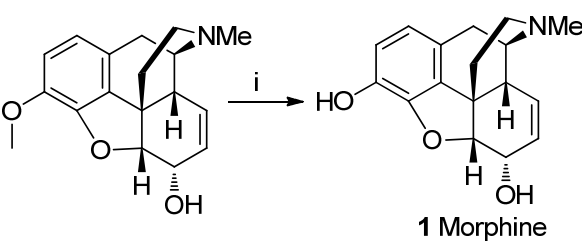

321

Reagents and conditions: (a) 313, then $\mathrm{NaBH}_{4}$, then aq. citric acid, $86 \%$; (b) $315, \mathrm{Pd}(\mathrm{dppf}) \mathrm{Cl}_{2} \cdot \mathrm{CH}_{2} \mathrm{Cl}_{2}, 58 \%$; (c) $\mathrm{hv}, 37 \%$; (d) aq. $\mathrm{KOH}$, then $\mathrm{Na}_{2} \mathrm{RuO}_{4}$; (e) Ohira-Bestmann reagent, $\mathrm{K}_{2} \mathrm{CO}_{3}$, then $\mathrm{Me}(\mathrm{MeO}) \mathrm{NHHCl}$, NMM, DMTMM, 73\% two steps; (f) Vinylmagnesium bromide, 87\%; (g) Hoveyda-Grubbs cat; (h) TFA, then aq. $\mathrm{Na}_{2} \mathrm{CO}_{3}$, then $\mathrm{NaBH}_{4} ; 65 \%$ two steps; (i) $\mathrm{BBr}_{3}, 86 \%$.

图式 32 Smith 研究组的合成方法

Scheme 32 Synthesis by Smith's group 
表 1 吗啡类生物碱的合成总结

Table 1 Summary of syntheses of morphine alkaloids

\begin{tabular}{|c|c|c|c|c|}
\hline Principle author & Year & Target & Steps & Overall yield $/ \%$ \\
\hline Gates & 1952 & Morphine & 31 & 0.06 \\
\hline Ginsberg & 1954 & rac-Dihydrothebainone & 21 & 8.9 \\
\hline Grewe & 1967 & rac-Dihydrothebainone & 9 & 0.81 \\
\hline Rice & 1980 & Dihydrocodeinone & 14 & 29.7 \\
\hline Evans & 1982 & rac-O-Me-thebainone $\mathrm{A}$ & 12 & 16.7 \\
\hline White & 1983 & Codeine & 8 & 1.8 \\
\hline Rapoport & 1983 & rac-Codeine & 26 & 1.2 \\
\hline Fuchs & 1987 & rac-Codeine & 23 & 1.3 \\
\hline Tius & 1992 & $r a c$-Thebainone-A & 24 & 1.1 \\
\hline Parker & 1992 & $r a c$-Dihydrocodeineone & 11 & 11.1 \\
\hline Overman & 1993 & Dihydrocodeinone & 14 & 1.9 \\
\hline Mulzer & 1998 & Dihydrocodeinone & 15 & 9.1 \\
\hline White & 1999 & ent-Morphine & 28 & 3.0 \\
\hline Cheng & 2000 & rac-Desoxycodeine-D & 15 & 13.26 \\
\hline Ogasawara & 2000 & $r a c-3,4-D i m e t h o x y-6-m o r p h i n a n o n e$ & 29 & 0.25 \\
\hline Ogasawara & 2001 & Dihydrocodeinone ethylene ketal & 21 & 1.5 \\
\hline Taber & 2002 & Morphine & 27 & 0.51 \\
\hline Trost & 2002 & Codeine & 15 & 6.8 \\
\hline Fukuyama & 2006 & rac-Morphine & 25 & 6.7 \\
\hline Hudlicky & 2007 & ent-Codeine & 15 & 0.23 \\
\hline Iorga/Guillou & 2008 & rac-Codeine & 17 & 0.64 \\
\hline Chida & 2008 & $r a c$-Dihydroisocodeine & 24 & 3.8 \\
\hline Hudlicky & 2009 & Codeine & 18 & 0.19 \\
\hline Magnus & 2009 & rac-Codeine & 13 & 20.1 \\
\hline Stork & 2009 & rac-Codeine & 22 & 2.0 \\
\hline Fukuyama & 2010 & Morphine & 18 & 4.8 \\
\hline Metz & 2011 & $r a c$-Codeine & 20 & 2.8 \\
\hline Fukuyama & 2014 & $(-)$-Oxycodone & 21 & 2.4 \\
\hline Hudlicky & 2014 & ent-Hydromorphone & 12 & 4.8 \\
\hline Opatz & 2014 & $(-)$-dihydrocodeine & 10 & 35 \\
\hline Zhang & 2015 & rac-Codeine & 14 & 3.6 \\
\hline Smith & 2016 & rac-Morphine & 10 & 6.6 \\
\hline
\end{tabular}

方法和策略不管是对吗啡及其生物碱的全合成还是对 整个有机合成化学的发展都起到了重要的意义. 迄今为 止, 吗啡的全合成路线还不具备实用意义和生产价值, 现今使用的吗啡仍需要从天然产物中获取, 因此, 现代 有机合成家们还需要为寻找到一个更为简单, 新颖和快 速合成吗啡的方法继续努力.

\section{Referenes}

[1] Herbert, R. B.; Venter, H.; Pos, S. Nat. Prod. Rep. 2000, 17, 317.

[2] Reed, J. W.; Hudlicky, T. Acc. Chem. Res. 2015, 48, 674.

[3] Gum, A.; Stabile, M. In Studies in Natural Products Chemistry, Vol. 18, Elsevier, Amsterdam, 1996, pp. 43 154 .

[4] Novak, B. H.; Hudlicky, T.; Reed, J. W.; Mulzer, J.; Trauner, D. Curr. Org. Chem. 2000, 4, 343.

[5] Blakemore, P. R.; White, J. D. Chem. Commun. 2002, 1159.

[6] Zezula, J.; Hudlicky, T. Synlett 2005, 388.

[7] Taber, D. F.; Neubert, T. D.; Schlecht, M. F. In Strategies and Tactics in Organic Synthesis, Vol. 5, Ed.: Harmata, M., Elsevier, London, 2004, pp. 353 389 .

[8] Chida, N. Top. Curr. Chem. 2010, 299, 1.
[9] Rinner, U.; Hudlicky, T. Top. Curr. Chem. 2012, 309, 33.

[10] Gates, M.; Tschudi, G. J. Am. Chem. Soc. 1952, 74, 1109

[11] Gates, M.; Tschudi, G. J. Am. Chem. Soc. 1956, 78, 1380.

[12] Gulland, J. M.; Robinson, R. Mem. Proc. Manchester Lit. Philos. Soc. 1925, 69, 79.

[13] Elad, D.; Ginsburg, D. J. Chem. Soc. 1954, 3052.

[14] Barton, D. H. R. Pure Appl. Chem. 1964, 9, 35.

[15] Kutchan, T. M. Alkaloids Chem. Biol. 1998, 50, 257.

[16] Szantay, C.; Barczai, B. M.; Pechy, P.; Blasko, G.; Dornyei, G. J. Org. Chem. 1982, 47, 594.

[17] White, J. D.; Caravatti, G.; Kline, T. B.; Edstrom, E.; Rice, K. C.; Brossi, A. Tetrahedron 1983, 39, 2393.

[18] Schwartz, M. A. J. Org. Chem. 1988, 53, 2318.

[19] Grewe, R.; Friedriccsen, W. Chem. Ber. Recl. 1967, 100, 1550.

[20] Grewe, R.; Fischer, H.; Friedric, W. Chem. Ber. Recl. 1967, 100, 1.

[21] Rice, K. C. J. Org. Chem. 1980, 45, 3135.

[22] White, J. D.; Caravatti, G.; Kline, T. B.; Edstrom, E.; Rice, K. C.; Brossi, A. Tetrahedron 1983, 39, 2393.

[23] Ludwig, W.; Schafer, H. J. Angew. Chem., Int. Ed. Engl. 1986, 25, 1025.

[24] Evans, D. A.; Mitch, C. H. Tetrahedron Lett. 1982, 23, 285.

[25] Moos, W. H.; Gless, R. D.; Rapoport, H. J. Org. Chem. 1983, 48, 227.

[26] Schultz, A. D.; Lucci, R. D.; Napier, J. J.; Kinoshita, H.; Ravichan- 
dran, R.; Shannon, P.; Yee, Y. K. J. Org. Chem. 1985, 50, 217.

[27] Toth, J. E.; Fuchs, P. L. J. Org. Chem. 1987, 52, 473.

[28] Tius, M. A.; Kerr, M. A. J. Am. Chem. Soc. 1992, 114, 5959.

[29] Parker, K. A.; Fokas, D. J. Am. Chem. Soc. 1992, 114, 9688.

[30] Parker, K. A.; Fokas, D. J. Org. Chem. 2006, 71, 449.

[31] Hong, C. Y.; Kado, N.; Overman, L. E. J. Am. Chem. Soc. 1993, $115,11028$.

[32] Trauner, D.; Bats, J. W.; Werner, A.; Mulzer, J. J. Org. Chem. 1998, 63, 5908.

[33] White, J. D.; Hrnciar, P.; Stappenbeck, F. J. Org. Chem. 1999, 64, 7871.

[34] Liou, J. P.; Cheng, C. Y. Tetrahedron Lett. 2000, 41, 915.

[35] Yamada, O.; Ogasawara, K. Org. Lett. 2000, 2, 2785.

[36] Nagata, H.; Miyazawa, N.; Ogasawara, K. Chem. Commun. 2001, 1094.

[37] Taber, D. F.; Neubert, T. D.; Rheingold, A. L. J. Am. Chem. Soc. 2002, 124, 12416.

[38] Trost, B. M.; Tang, W. P. J. Am. Chem. Soc. 2002, 124, 14542.

[39] Trost, B. M.; Tang, W. P.; Toste, F. D. J. Am. Chem. Soc. 2005, 127, 14785.

[40] Uchida, K.; Yokoshima, S.; Kan, T.; Fukuyama, T. Org. Lett. 2006, 8,5311 .

[41] Omori, A. T.; Finn, K. J.; Leisch, H.; Carroll, R. J.; Hudlicky, T.
Synlett 2007, 2859

[42] Tanimoto, H.; Saito, R.; Chida, N. Tetrahedron. Lett. 2008, 49, 358.

[43] Varin, M.; Barre, E.; Iorga, B.; Guillou, C. Chem. Eur. J. 2008, 14, 6606.

[44] Stork, G.; Yamashita, A.; Adams, J.; Schulte, G. R.; Chesworth, R.; Miyazaki, Y.; Farmer, J. J. J. Am. Chem. Soc. 2009, 131, 11402.

[45] Magnus, P.; Sane, N.; Fauber, B. P.; Lynch, V. J. Am. Chem. Soc. 2009, 131, 16045 .

[46] Erhard, T.; Ehrlich, G.; Metz, P. Angew. Chem., Int. Ed. 2011, 50, 3892.

[47] Li, J.; Liu, G. L.; Zhao, X. H.; Du, J. Y.; Qu, H.; Chu, W. D.; Ding, M.; Jin, C. Y.; Wei, M. X.; Fan, C. A. Chem.-Asian J. 2013, 8, 1105 .

[48] Kimishima, A.; Umihara, H.; Mizoguchi, A.; Yokoshima, S.; Fukuyama, T. Org. Lett. 2014, 16, 6244.

[49] Tissot, M.; Phipps, R. J.; Lucas, C.; Leon, R. M.; Pace, R. D.; Ngouansavanh, T.; Gaunt, M. J. Angew. Chem., Int. Ed. 2014, 53, 13498.

[50] Arghese, V.; Hudlicky, T. Angew. Chem., Int. Ed. 2014, 53, 4355.

[51] Geffe, M.; Opatz, T. Org. Lett. 2014, 16, 5282.

[52] Li, Q. L.; Zhang, H. B. Chem. Eur. J. 2015, 21, 16379.

[53] Chu, S.; Mgnster, N.; Balan, T.; Smith, M. D. Angew. Chem., Int. Ed. 2016, 55, 14306. 